\title{
Effect of plasma treatment on accelerated PLA degradation
}

\author{
A. Antunes, A. S. Luyt, P. Kasak, O. Aljarod, M. K. Hassan, A. Popelka* \\ Center for Advanced Materials, Qatar University, P.O. Box 2713, Doha, Qatar
}

Received 19 November 2020; accepted in revised form 11 February 2021

\begin{abstract}
Poly(lactic acid) (PLA) has been found to be important in various applications, such as in the medical, pharmaceutical, and packaging industries. However, the long-term associated degradation process of PLA is a limiting factor for some applications. Therefore, in this research, the influence of corona and radio-frequency (RF) surface plasma treatment on the degradation of PLA in accelerated weathering tests was studied. The accelerated weathering test was applied using standard UV irradiation for up to $2000 \mathrm{~h}$. The morphological/topographical, chemical, crystallization, mechanical, and thermal changes were analyzed after 500,1000, and $2000 \mathrm{~h}$ of accelerated weathering time. The introduction of the polar functional groups caused by plasma treatment on the PLA surface improved its wettability, and therefore, hydrolytic degradation was promoted over the accelerated weathering time. It was revealed that the plasma treatment enhanced the hydrolytic and UV degradation of the PLA, as was confirmed by investigation of the physical, chemical, mechanical, and thermal properties. Moreover, the RF plasma was more pronounced than the corona plasma in the degradation of the PLA. Such an approach represents a pathway to promote and tailor PLA degradation.
\end{abstract}

Keywords: biodegradable polymers, plasma treatment, accelerated degradation, wettability, mechanical properties

\section{Introduction}

Poly(lactic acid) (PLA) is an aliphatic thermoplastic polyester that is considered environmentally friendly. It is derived from renewable plant resources and offers properties comparable to petrochemical-based polymers, but it is biodegradable [1-4]. However, PLA has a very slow biodegradation rate at temperatures less than its $T_{\mathrm{g}}[2,5-7]$. In terms of its physicomechanical properties, PLA is a favorable polymer with good mechanical properties, exhibiting good strength and modulus but low thermal stability [8]. In fact, this polymer is useful for different applications, such as for medical uses, for pharmaceuticalcontrolled release, and in biodegradable packaging due to its excellent biocompatibility and biodegradability under appropriate conditions $[7,9,10]$.

Knowledge of the degradation of PLA is crucial for treating plastic waste and easing the severe plastic crisis, as PLA has been proposed as an alternative for oil-based polymers. Despite the fact that the biodegradation of PLA takes place in the soil, where humidity and microorganisms exist, a period longer than two months is still required for its decomposition [11]. Thus, several studies have been conducted in recent years looking for more efficient methods to accelerate the degradation rate of PLA through the use of microorganisms [12], fillers and fibers [11, 13-17], wet solutions [18-20], and UV catalyzers $[2,8,21]$ to control the degradation process in different media.

Another strategy to tailor a polymer material is a chemical modification by introducing specific functional groups on the surface. The most common are wet chemical processes, which are fast and cheap. However, most of them show more undesirable effects than advantages, such as the toxicity of some solutions and hazardous chemical waste, non-homogeneous irregularity of the surface due to etching and 
erosion, as well as a loss of mechanical properties. In contrast, solvent-free techniques involving dryroute strategies such as ozone oxidation, gammaand UV-radiation, and plasma treatments should be considered for the incorporation of functional groups on the surfaces of biodegradable materials [22].

The surface modification of biodegradable polymers using low-temperature plasma discharge can positively affect the (bio)degradability of biomaterials. Plasma treatment is responsible for an increase in wettability, which results in an enhancement of the biodegradability through the incorporation of new polar functional groups, such as the hydroxyl, carboxyl, and carbonyl functional groups, into the polymer backbone chain. Chang and Chian [23] confirmed that plasma-modified chitosan films possess enhanced biodegradability compared to unmodified chitosan films. This behavior is caused by the metabolization of more hydroxyl and carboxylic acid groups during biodegradation, which are incorporated onto the surface during the plasma treatment process. Fabbri et al. [24] used low-temperature plasma to modify the surface of a poly(butylene succinate)-based copolymer, which improved the hydrolytic degradation rate and the biocompatibility. Plasma etching was responsible for an enhancement in the polymer wettability, resulting in an increased hydrolytic degradation rate, while the bulk properties remained unchanged. Song et al. [25] studied the effects of low-temperature plasma treatment on the biodegradable and physicochemical properties of PLA during 56 days of storage time. The wettability, photodegradation, thermal, and microbial biodegradability properties of the modified PLA films were remarkably enhanced.

There are only a few studies related to the effect of plasma treatment on the degradation of PLA. Herein, and to the best of our knowledge, this study is the first to combine both plasma treatment with accelerated weathering degradation of PLA. The effect of two different types of plasma treatment on the accelerated weathering degradation of PLA across $2000 \mathrm{~h}$ was extensively studied. Corona and radio-frequency (RF) plasma treatments were applied to treat the PLA surface in order to promote the degradation process. The samples were analyzed by various analytical, spectroscopic, and microscopic techniques to investigate the chemical, physical, and mechanical changes in the combined effect of plasma treatment and accelerated weathering degradation.

\section{Experimental}

\subsection{Materials}

The PLA used in this study was a biopolymer with a high molar mass (Ingeo ${ }^{\mathrm{TM}}$ Biopolymer 2003D), obtained from NatureWorks, LLC (Minnetonka, $\mathrm{MN}, \mathrm{USA}$ ). It was transparent with a density of $1.24 \mathrm{~g} \cdot \mathrm{cm}^{-3}$, a melt flow index of $6.0 \mathrm{~g} / 10 \mathrm{~min}$ $\left(2.16 \mathrm{~kg}\right.$ and $\left.210^{\circ} \mathrm{C}\right)$, a glass transition of $\sim 55^{\circ} \mathrm{C}$, and a melting temperature of $\sim 150^{\circ} \mathrm{C}$.

Ethylene glycol ( $>98 \%$ FLUKA, Morris Plains, New Jersey, USA), formamide ( $>98 \%$ FLUKA), and ultrapure water (prepared by Purification System Direct Q3, Millipore Corporation, Molsheim, France) were used as the testing liquids for the wettability analyses.

\subsection{Sample preparation}

The neat PLA was placed between two stainless steel plates covered by a release foil and molded into $1 \mathrm{~mm}$ thick sheets at $170^{\circ} \mathrm{C}$ for 5 min using a mounting hot press machine (Carver, Inc., Wabash, Indiana, USA) at a pressure of 50 bar. The sheets were allowed to cool down by water to room temperature and then cut into dumbbell and rectangular shapes as further described.

\subsection{Plasma treatment}

The corona CVE-L system (Softal, Germany), working at atmospheric pressure, was used for the surface treatment of the PLA samples under dynamic conditions. This system generates corona discharge in an air atmosphere using a 7010 generator (Softal, Germany) with a maximum of $300 \mathrm{~W}$ of nominal power and a $20.8 \mathrm{kHz}$ frequency at $8.4 \mathrm{~A}$ of output current. The corona system consists of a set of powered metal electrodes embedded in a ceramic insulator for the optimal isolation of high voltage, allowing treatment of a $29.70 \times 1.35 \mathrm{~cm}^{2}$ surface area. A planar sample holder made of porous aluminum with suction control kept the samples in the right position during the treatment. A high-efficiency catalytic ozone removal system was part of this system for an efficient ozone extraction, ensuring a safe working environment. The plasma treatment process of the PLA samples was optimized in terms of treatment times that varied from 1 to $12 \mathrm{~s}$ using $300 \mathrm{~W}$ of nominal power, and $1 \mathrm{~mm}$ was the distance between the electrodes and the sample holder.

A Venus75-HF plasma system (PlasmaEtch, USA), working under vacuum $(\sim 27 \mathrm{~Pa})$ and at a $13.56 \mathrm{MHz}$ 
frequency, was used for the surface treatment of the PLA samples under static conditions. This equipment consisted of a cylindrical chamber made of aluminum ( $25 \mathrm{~cm}$ in diameter and $28 \mathrm{~cm}$ depth). A capacitive parallel plate design allowed generating nominal power with a maximum of $120 \mathrm{~W}$. All of the operational parameters were fully controllable by the PC software, such as the treatment time or nominal power, for achieving an optimal plasma treatment process of the samples. The RF plasma treatment of the PLA samples was first optimized in terms of various treatment times (15-180 s) prior to the accelerated degradation studies.

\subsection{Accelerated weathering aging}

Accelerated weathering of the plasma-treated samples, i.e., the corona- and RF-treated PLA samples, were conducted in an accelerated weathering tester QUV/se model (Q-LAB, Westlake, Ohio, USA). The weathering conditions followed the Cycle-C of the ASTM D4329 standard. Fluorescent UV lamps (UVA-340) with a $0.76 \mathrm{~W} \cdot \mathrm{m}^{-2}$ irradiance (a $340 \mathrm{~nm}$ wavelength) were used with cycles of $8 \mathrm{~h} \mathrm{UV}$ irradiation at $50{ }^{\circ} \mathrm{C}$, followed by $4 \mathrm{~h}$ of dark at $50^{\circ} \mathrm{C}$ under $100 \%$ condensing humidity. These consecutive cycles were applied to the specimens attached to the test panels without any interruption. The effects of the accelerated weathering were investigated for four exposure periods: $0,500,1000$, and $2000 \mathrm{~h}$. Samples were collected for analysis after each period, and they were designated as 'PLA/xh', 'PLA/ Corona/xh,' or 'PLA/RF/xh' for the neat, corona-, and RF-treated PLA samples, respectively, where $x$ denotes the accelerated weathering period in hours.

\subsection{Wettability analysis}

A video-based optical contact angle measuring system, i.e., OCA35 (DataPhysics, Germany), was used to measure the surface wettability changes of the PLA samples after plasma treatment, and the aging effect was measured using the sessile drop technique. Testing liquids with different surface tensions, such as water, formamide, and ethylene glycol, were used to evaluate the surface free energy of the untreated and treated samples to determine their wettability. A $3 \mu 1$ volume of testing liquids was used to eliminate gravitational effects. Surface free energy $\left(\gamma_{\mathrm{s}}\right)$, including its polar $\left(\gamma_{\mathrm{s}}^{\mathrm{p}}\right)$ and dispersive $\left(\gamma_{\mathrm{s}}^{\mathrm{d}}\right)$ components (Equation (1)), were evaluated with the SCA20 software using the Owens-Wendt-Rabel-Kaelble regression model [26] by application of a geometric mean (Equation (2)). The subsequent substitution in Young's equation (Equation (3)) was used to obtain a linear equation of the type $y=m x+c$ (Equation (4)), which was used for the evaluation of the surface free energy of the prepared and treated polymer nanocomposite samples:

$$
\begin{aligned}
& \gamma_{s}=\gamma_{s}^{\mathrm{p}}+\gamma_{\mathrm{s}}^{\mathrm{d}} \\
& \gamma_{\mathrm{sl}}=\gamma_{\mathrm{s}}-\gamma_{1}-2 \sqrt{\gamma_{\mathrm{s}}^{\mathrm{d}} \gamma_{1}^{\mathrm{d}}}-2 \sqrt{\gamma_{\mathrm{s}}^{\mathrm{p}} \gamma_{1}^{\mathrm{p}}} \\
& \gamma_{\mathrm{s}}=\gamma_{\mathrm{sl}}+\gamma_{1} \cos \theta \\
& \frac{\gamma_{\mathrm{l}}(1+\cos \theta)}{2 \sqrt{\gamma_{1}^{\mathrm{d}}}}=\sqrt{\gamma_{\mathrm{s}}^{\mathrm{p}}} \cdot \sqrt{\frac{\gamma_{1}^{\mathrm{p}}}{\gamma_{1}^{\mathrm{d}}}}+\sqrt{\gamma_{\mathrm{s}}^{\mathrm{d}}}
\end{aligned}
$$

where $\left(\gamma_{\mathrm{s}}^{\mathrm{p}}\right)$ and $\left(\gamma_{\mathrm{s}}^{\mathrm{d}}\right)$ are the polar and dispersive parts of the surface energy of the solid $\left(\gamma_{\mathrm{s}}\right)$, respectively, and $\left(\gamma_{1}^{\mathrm{p}}\right)$ and $\left(\gamma_{1}^{\mathrm{d}}\right)$ are the polar and dispersive parts of the surface tension of the liquid $\left(\gamma_{1}\right)$, respectively. The reported value for each testing liquid corresponds to the mean of at least five measurements taken on different parts of the substrate surface.

\subsection{Surface morphology analysis}

The surface morphology changes of the plasmatreated and degraded samples were investigated using scanning electron microscopy (SEM). The Nova NanoSEM 450 (FEI, USA) SEM equipment was used for this purpose. A very thin Au layer (a few nanometers) was sputter-coated onto the sample surface to ensure a high resolution of the resulting SEM images in 2D scale as elimination of electron accumulation on the analyzed surface.

Detailed information about the surface topography of the PLA samples in 3D scale was obtained using atomic force microscopy (AFM). The MFP-3D (Asylum Research, USA) AFM device, using an AC160TS silicon probe (Al reflex-coated Veeco model; OLTESPA, Olympus, Japan), was employed to capture high-resolution AFM images $(512 \times 512$ points) using a non-contact tapping mode in air under ambient conditions. The surface roughness was also evaluated by the $R_{\mathrm{a}}$ parameter considering the average height of the irregularities relative to the sample surface in a perpendicular direction. Moreover, the height variations on the surface ( $z$-axis) were evaluated by line profiles from ZSensor. 


\subsection{Structural analysis}

X-ray diffraction (XRD) analyses were performed using an Empyrean (Panalytical, Almelo, The Netherlands) equipped with a $\mathrm{Cu} \mathrm{K}_{\alpha}(\lambda=0.1540 \mathrm{~nm})$ source to analyze structural properties of the PLA samples in terms of crystalline and amorphous phases. The XRD generator was operated at $40 \mathrm{~mA}$ and $45 \mathrm{kV}$. Samples were scanned from 5 to $80^{\circ}$ at a scanning rate of $0.0130^{\circ} 2 \theta$.

\subsection{Chemical composition analysis}

Qualitative analyses of the chemical composition changes in the PLA samples after plasma treatment and accelerated weathering were carried out by Fourier transform infrared spectroscopy (FTIR) using an attenuated total reflectance accessory. FTIR Spectrometer Frontier (PerkinElmer, MA, USA) was used for obtaining the spectra in the middle infrared region (4000-400 $\mathrm{cm}^{-1}$ ) using a ZnSe crystal, allowing a $1.66 \mu \mathrm{m}$ penetration depth with an average of 8 scans and a resolution of $4 \mathrm{~cm}^{-1}$. Good contact between the analyzed samples and the crystal was ensured using a pressure clamp, allowing to obtain a high spectral quality.

\subsection{Molecular size analysis}

The average molecular number $\left(M_{\mathrm{n}}\right)$ and weight $\left(M_{\mathrm{w}}\right)$, as well as the molar mass dispersity $\left(\bigoplus_{\mathrm{M}}\right)$, were determined using gel permeation chromatography/size exclusion chromatography (GPC/SEC) equipped with a Wyatt Mini Dawn (Wyatt Technology Corporation, Santa Barbara, CA, USA) multiangle light scattering detector and a $100 \mu \mathrm{l}$ Waters Alliance 2695 autoinjector (Waters, Elstree, U.K.). The columns were Agilent PL-gel Mixed-D (Agilent, Santa Clara, CA, USA) with a pore size of $5 \mu \mathrm{m}$ and a particle size of $2 \mu \mathrm{m}$, conditioned at $160^{\circ} \mathrm{C}$ using an external oven. The flow rate was $1 \mathrm{ml} \cdot \mathrm{min}^{-1}$, and ultrapure tetrahydrofuran (THF) was used as the mobile phase. The plasma-treated PLA samples for analysis were prepared by dissolving a small amount of polymer $\left(35 \mathrm{mg} \cdot \mathrm{ml}^{-1}\right)$ in THF, followed by vigorous stirring for $30 \mathrm{~min}$. Subsequently, the sample was filtered through a $0.45 \mathrm{~mm}$ nylon filter, and then the sample was injected.

\subsection{Thermal analysis}

Differential scanning calorimetry (DSC) analyses were performed using a DSC8500 (PerkinElmer, Waltham, MA, USA) differential scanning calorimeter.
The PLA samples $(5-10 \mathrm{mg})$ were heated from 30 to $160^{\circ} \mathrm{C}$ at $10^{\circ} \mathrm{C} \cdot \mathrm{min}^{-1}$. The melting enthalpies of the PLA samples were determined from the DSC curves, and Equation (5) was used to calculate the degrees of crystallinity of the samples, where $\Delta H_{\mathrm{m}}$ is the measured melting enthalpy, $\Delta H_{\mathrm{cc}}$ is the measured cold crystallization enthalpy (which has a negative value because crystallization is exothermic therefore using $\left|\Delta H_{\mathrm{m}}\right|$ and $\left|\Delta H_{\mathrm{cc}}\right|$ in the Equation (5)), and $\Delta H_{\mathrm{m}}^{\circ}$ is the enthalpy of melting of the $100 \%$ crystalline polymer, with a value of $93.6 \mathrm{~J} \cdot \mathrm{g}^{-1}$ for PLA [27]:

$X_{\mathrm{c}}[\%]=\frac{\left|\Delta H_{\mathrm{m}}\right|-\left|\Delta H_{\mathrm{cc}}\right|}{\Delta H_{\mathrm{m}}^{\circ}} \cdot 100$

A TGA4000 (PerkinElmer, Waltham, MA, USA) thermogravimetric analyzer (TGA) was used to analyze the thermal degradation behavior of the samples. The analyses were done from 30 to $600{ }^{\circ} \mathrm{C}$ at a heating rate of $10^{\circ} \mathrm{C} \cdot \mathrm{min}^{-1}$ under nitrogen flow $\left(20 \mathrm{ml} \cdot \mathrm{min}^{-1}\right)$. The sample masses were $10-15 \mathrm{mg}$.

\subsection{Mechanical properties}

The tensile properties were determined at room temperature using a Lloyd LR $50 \mathrm{k}$ Plus (Lloyd Instruments, Ltd., Fareham, U.K.) universal testing machine at a stretching speed of $10 \mathrm{~mm} \cdot \mathrm{min}^{-1}$ (ASTM D638). The gauge length was $25 \mathrm{~mm}$, and the sample (dumbbell shape) width and thickness were 3.25 and $1 \mathrm{~mm}$, respectively.

AFM was used also to determine the mechanical properties of PLA samples using the amplitude modulation-frequency modulation (AM-FM) technique. This technique is an extension of standard AC mode (also known as AM-AFM), where the probe is excited simultaneously at its fundamental resonant frequency and another eigenmode. The fundamental resonance was used for obtaining of the topographical features of the PLA samples, whereas the mechanical properties were analyzed by tracking the frequency and amplitude shift of the another eigenmode. The measured frequency shift $\Delta f$ was used to evaluate the interaction stiffness $\left(\Delta k^{\mathrm{FM}}\right)$ by Equation (6):

$$
\Delta k^{\mathrm{FM}}=2 k_{\mathrm{c}} \cdot \frac{\Delta f}{f_{\mathrm{c}}}
$$

where $k_{\mathrm{c}}$ is the spring constant of the cantilever and $f_{\mathrm{c}}$ is the frequency of the eigenmode of the cantilever. To obtain the Young's modulus of the PLA samples, 
a general Hertz model was applied, describing the contact mechanics between the tip and the analyzed sample. A PLA standard with the known Young's modulus (3.04 GPa) was first used for the calibration of the cantilever to determine its elasticity, which was subsequently used for obtaining the absolute values of the Young's modulus of the analyzed PLA samples.

\section{Results and discussion}

\subsection{Plasma treatment optimization}

Wettability is closely related to the chemical composition and roughness of the top surface layer, and therefore, it is an important factor for the understanding of the degradation process in its initial step. The contact angles of testing liquids with different surface tensions were used for the evaluation of the total surface free energy, as well as its dispersive and polar components. The plasma treatment process was first optimized in terms of treatment time, varying from 1 to $12 \mathrm{~s}$ and from 15 to $180 \mathrm{~s}$ for the corona and RF plasma treatment, respectively. The untreated PLA sample showed relatively low contact angles and, therefore, quite high values of total surface free energy, as well as a high value of the polar component, indicating quite good wettability [28]. Plasma treatment of the PLA samples improved the wettability as a result of the incorporation of polar functional groups (hydrophilic) and roughness changes [29]. The corona treatment resulted in an improved wettability, while a large total surface free energy was achieved using a treatment time of $3 \mathrm{~s}$ (Figure 1a). The RF plasma treatment improved the wettability even more, with maximum contact angles achieved using a treatment time of $120 \mathrm{~s}$ (Figure 1b). These conditions were subsequently selected for treatment of the PLA samples in order to perform the

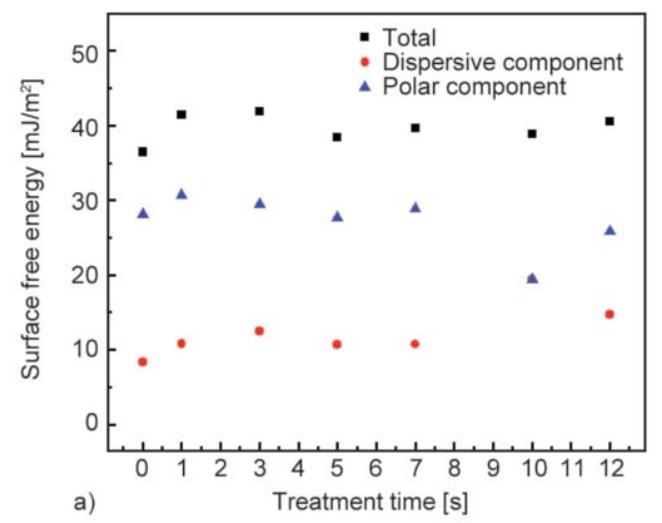

accelerated weathering aging test. Improved hydrophilicity of the plasma-treated PLA with an enhanced water content contributed to the accelerated hydrolytic degradation of the PLA samples [30].

\subsection{Surface morphology characterization}

Analysis of surface morphology/topography is important in order to understand the origin of the degradation process, which subsequently affects the layers below the surface, thereby resulting in a complex degradation. During the degradation, chain scission preferably occurs in the amorphous region, and crystalline domains can be formed [31]. The untreated and plasma-treated PLA samples initially exhibited transparency because of their amorphous character, which changed during the weathering exposure because of the formation of a semicrystalline structure [21]. The formed carboxylic end groups were then able to act as a catalyst for the degradation of PLA $[32,33]$. The information about the $2 \mathrm{D}$ surface morphology was obtained by SEM, and is summarized in Figure 2. The $2000 \mathrm{~h}$ of aging time led to a remarkable increase in roughness. The surface of the PLA sample was significantly affected by the degradation process, while micro-cracks, voids, and defects were clearly visible. These structural defects (cracks, cavities, and voids) are susceptible to subsequent UV and water penetration (hydrolytic degradation) to the deeper underneath layers, and therefore, the whole PLA bulk is affected, as was confirmed by other techniques, such as the DSC, XRD, and tensile tests. Plasma treatment of the PLA samples led to changes in the surface morphology as a result of the etching and ablation processes, while the presence of isles was more pronounced in the RF-treated PLA sample. This can be explained by the fact that the isles consisted of crystalline regions,

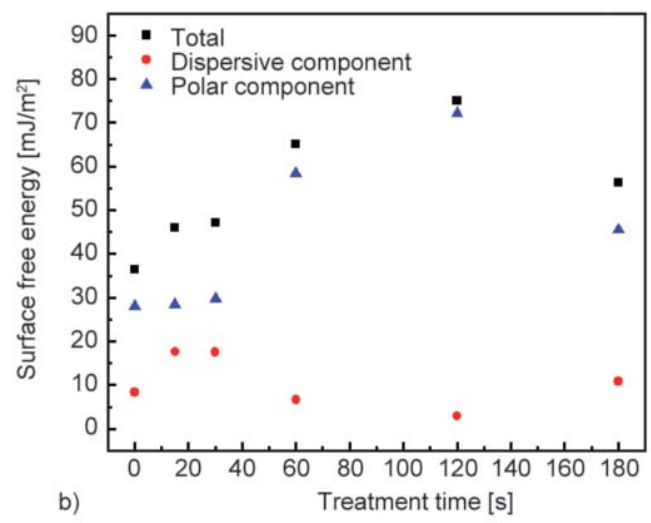

Figure 1. Surface free energy of: a) corona-treated and b) RF-treated PLA samples vs. treatment time. 

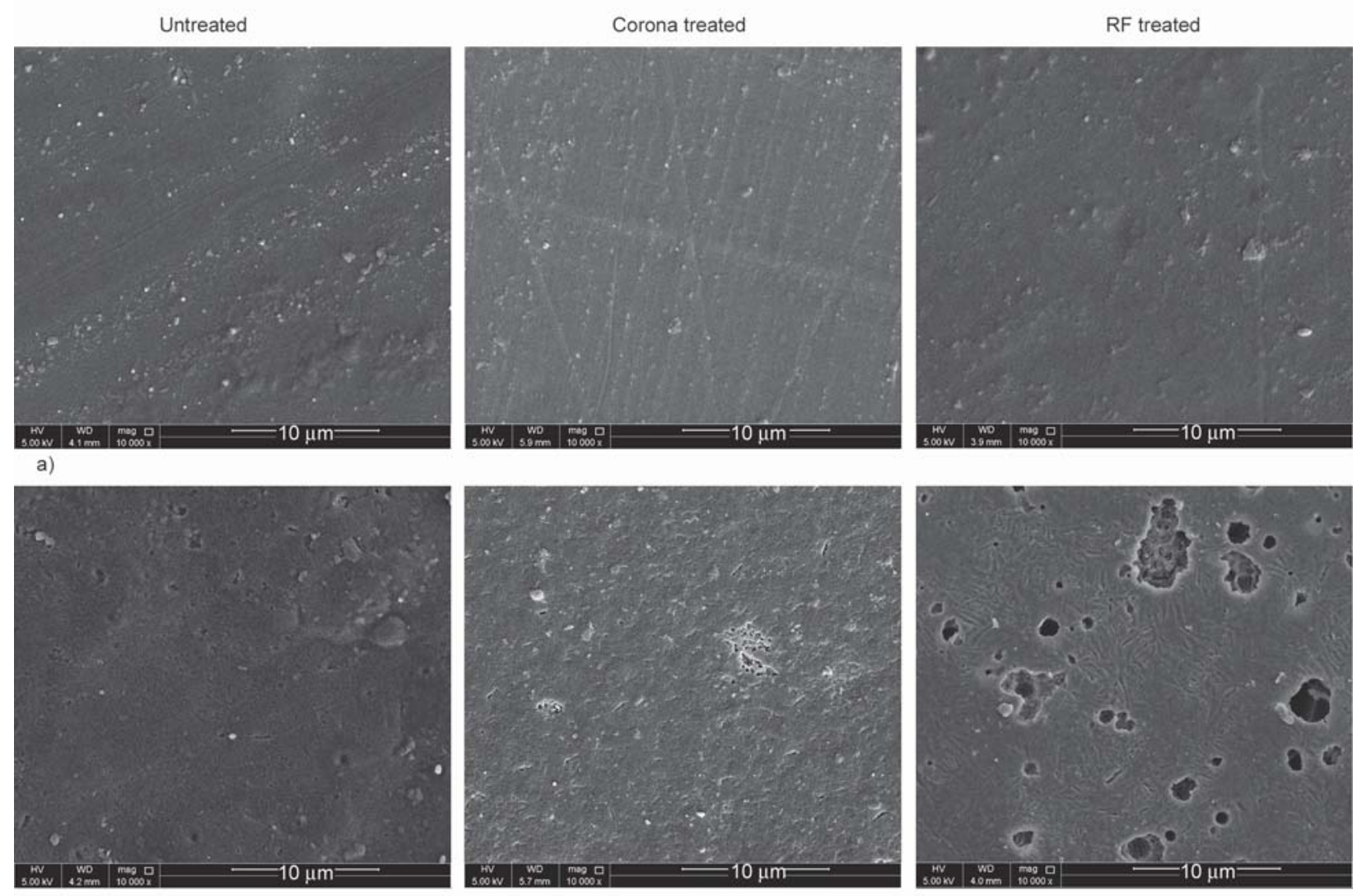

b)

Figure 2. Scanning electron microscopy (SEM) images of PLA samples (from left to right: Untreated, corona-, and RF-treated) at an accelerated weathering time: a) $0 \mathrm{~h}$ and b) $2000 \mathrm{~h}$.

as well as by the fact that the plasma treatment predominantly affected the amorphous regions [34]. Accelerated weathering aging $2000 \mathrm{~h}$ resulted in a remarkable increase in the surface roughness for the corona-treated PLA samples. The size and number of the cavities and isles were even larger for the RFtreated PLA samples after $2000 \mathrm{~h}$ of accelerated aging, confirming significant degradation in the outer surface area.

Detailed information about the topographical structures of the PLA samples in a $20 \times 20 \mu \mathrm{m}^{2}$ patch of the surface area was obtained using AFM (Figure 3). The untreated PLA sample showed a characteristic texture (agglomerates) in the relatively smooth surface area, while the $R_{\mathrm{a}}$ was $15.1 \mathrm{~nm}$. The $500 \mathrm{~h}$ of accelerated aging was responsible for a decrease in surface roughness $\left(R_{\mathrm{a}}=7.6 \mathrm{~nm}\right)$. The additional increase in aging time to $1000 \mathrm{~h}$ resulted in an increase in the surface roughness, while $R_{\mathrm{a}}$ achieved the highest value of $16.9 \mathrm{~nm}$. Aging time $2000 \mathrm{~h}$ led to a slight decrease in the surface roughness $\left(R_{\mathrm{a}}=12.5 \mathrm{~nm}\right)$.

The ablation and etching processes that occurred during the plasma treatment led to changes in the surface topography of the PLA samples while specific structures were formed. In the case of RF plasma treatment, the surface roughness slightly increased $\left(R_{\mathrm{a}}=17.1 \mathrm{~nm}\right)$, probably because of the presence of localized agglomerate regions, which were not affected by plasma etching. An aging time of $500 \mathrm{~h}$ also led to a decrease in the surface roughness of the plasma-treated PLA samples $\left(R_{\mathrm{a}}=14.2 \mathrm{~nm}\right)$. The $1000 \mathrm{~h}$ of aging time led to an increase in the surface roughness of the plasma-treated PLA, with almost identical values as in the case of untreated PLA/1000h. Meanwhile, $2000 \mathrm{~h}$ of aging time did not lead to any significant changes in the surface roughness of the corona-treated PLA sample, but slightly higher than in the case of the untreated PLA sample. However, the surface roughness of the RF-treated PLA sample achieved the highest values, with $R_{\mathrm{a}}$ equal to $70.0 \mathrm{~nm}$.

\subsection{Structural studies}

XRD was used to study the effect of accelerated weathering on the structural properties of the untreated and plasma-treated samples in terms of the resultant crystallinity. The XRD profiles of the PLA samples are given in Figure 4 for the different aging 

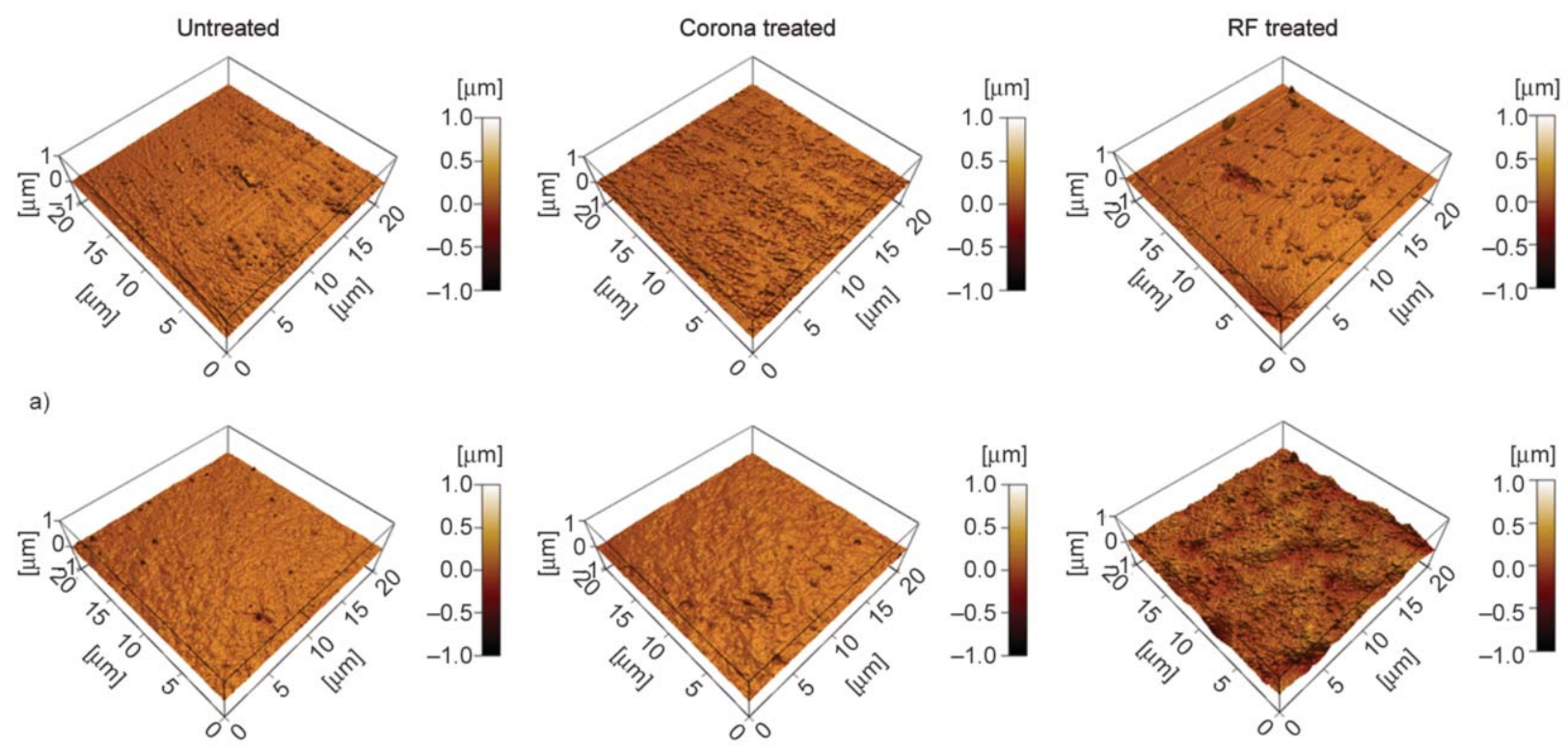

b)

Figure 3. Atomic force microscopy (AFM) images with line profiles of PLA samples: Untreated (left column), corona-treated (middle column), and RF-treated (right column) at accelerated weathering times: a) $0 \mathrm{~h}$ and b) $2000 \mathrm{~h}$.

times. The corona- and RF-treated PLA samples, as well as the untreated PLA, appear completely amorphous without any recognizable peaks before weathering. Only after $500 \mathrm{~h}$ of weathering, the RF-treated samples show two peaks observed at the $2 \theta$ values around 16.4 and $18.7^{\circ}$, which correspond to the $(200 / 110)$ and (203) planes from the crystalline structure of PLA, while the corona-treated samples remained as amorphous as untreated PLA.

Sharp peaks clearly appeared in the corona-treated samples after $1000 \mathrm{~h}$ of weathering, whereas at the same period, only minor peaks were noted in the RFtreated samples around 14.7, 22.2, 24.4, and $28.7^{\circ}$. These peaks are assigned to the (110), (300/030), and
(220) planes, indicating that the PLA contained both $\mathrm{D}$ and $\mathrm{L}$ isomers [35].

The intensity of all of the observed peaks increased with weathering time for both plasma treatments. The same evolution was noticed for neat PLA [21]. However, it was clearly seen that the RF-treated PLA degraded more rapidly than the corona-treated PLA, which was indicated by the earlier conversion of the amorphous character of the PLA to a semicrystalline one. It is known that amorphous regions are first attacked during hydrolytic degradation, followed by crystalline regions. The mobile shorter chains formed during hydrolytic and UV degradation allow for the reorientation of the crystalline phase, which results
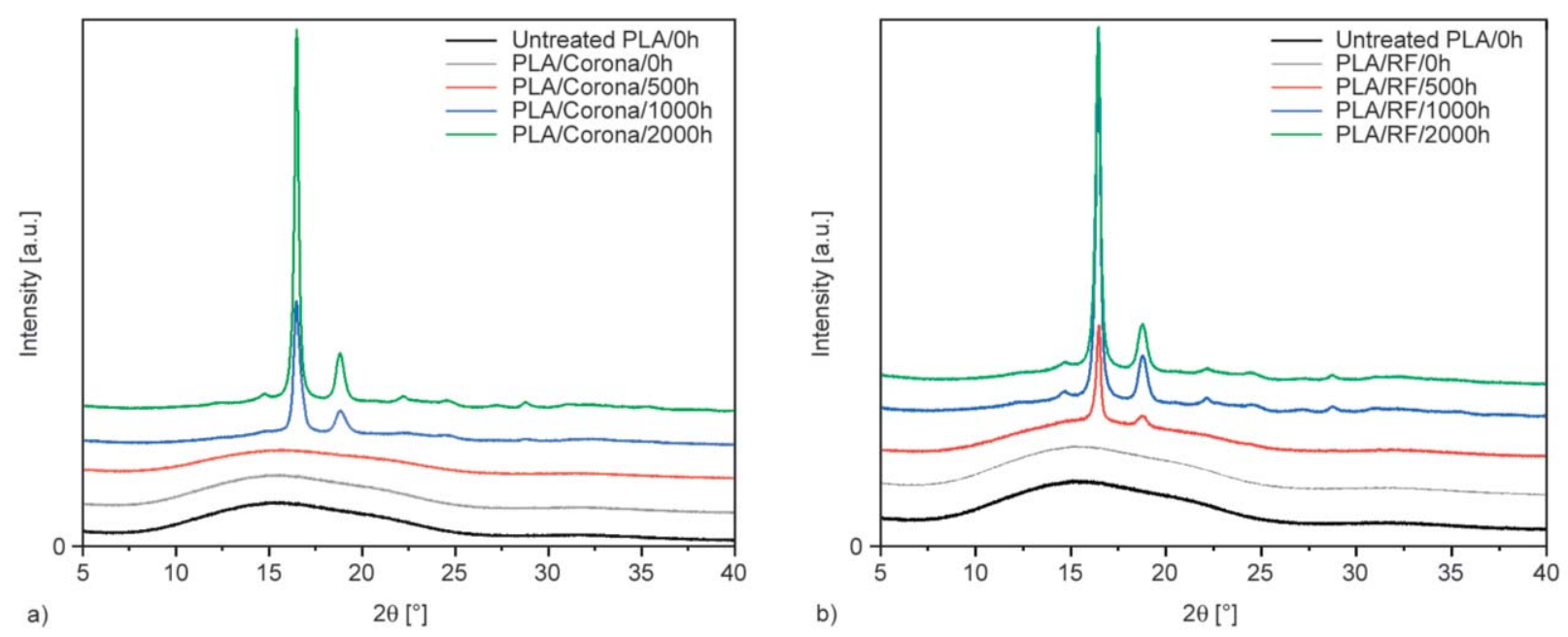

Figure 4. X-ray diffraction (XRD) spectra of PLA samples treated by a) corona plasma and b) RF plasma. 
in an increase in crystallinity [21]. The change in the XRD diffraction patterns showed that the RF treatment of the PLA surface accelerated the degradation processes and, consequently, the crystallization behavior of PLA, which is in accordance with the further discussion suggesting that plasma treatment contributes to the degradation of PLA.

\subsection{Wettability analysis}

The effect of aging time on changes in the polar component of the surface free energy of untreated and plasma-treated PLA samples is summarized in Figure 5. The wettability of the untreated and plasmatreated PLA samples decreased with increasing time during the first $1000 \mathrm{~h}$ of aging. This phenomenon can be explained by the rotation and diffusion of the plasma-formed polar functional groups [36] or the degraded oxygen-containing species into the deeper layers below the surface of the PLA. This wettability deterioration can be also described by the diffusion of water from the top surface into the bulk $[37,38]$. The diffusion of water into the polymer is much faster than hydrolytic degradation [37]. After $2000 \mathrm{~h}$ of aging, the wettability of the untreated PLA samples decreased even more, while the improved wettability of the plasma-treated PLA samples was probably caused by defects (cracks) and an increase in roughness, as was confirmed by microscopic analysis.

\subsection{Chemical composition analysis}

FTIR spectroscopy was used to analyze the possible chemical changes in the plasma-treated PLA samples during accelerated weathering, such as the carbonyl and polar groups' content, or new bands indicating the degradation of the PLA. The characteristic

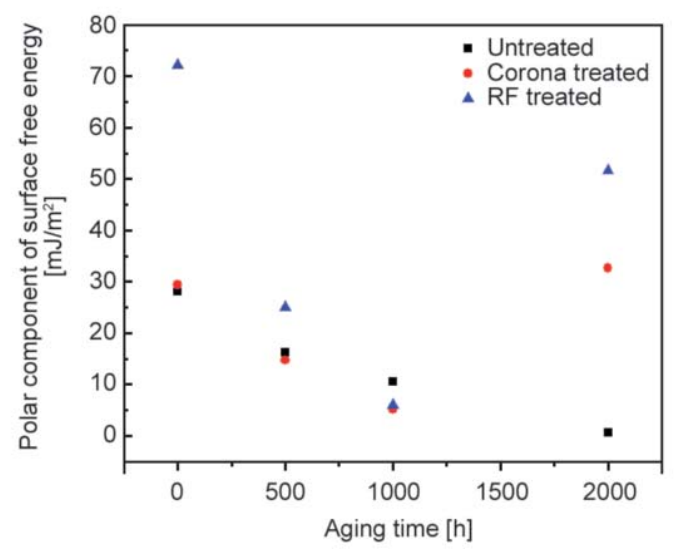

Figure 5. The polar component of the surface free energy of PLA samples vs. accelerated weathering time. absorption bands of the neat PLA were observed at $1747 \mathrm{~cm}^{-1}$, attributed to the stretching vibration of the carbonyl groups $(\mathrm{C}=\mathrm{O}$ in the $-\mathrm{CO}-\mathrm{O}-$ group $)$; the characteristic spectra of $\mathrm{C}-\mathrm{O}-\mathrm{C}$ occurred in the $1050-1250 \mathrm{~cm}^{-1}$ region and the bands positioned at 1452,1382 , and $1360 \mathrm{~cm}^{-1}$ were due to the asymmetric and symmetric deformation of $\mathrm{CH}_{3}[13,16,39$ 41]. The region of $2800-3000 \mathrm{~cm}^{-1}$ was assigned to the asymmetric and symmetric stretching mode of the $\mathrm{CH}_{3}$ and $\mathrm{CH}_{2}$ groups. The FTIR spectra of the neat, corona-, and RF-treated PLA samples are compared in Figure 6. The corona and RF plasma treatment simultaneously broke up the $\mathrm{C}-\mathrm{H}$ and $\mathrm{C}-\mathrm{C}$ bonds, resulting in etching/ablation and functionalization reactions in the PLA surface area [42]. Moreover, the formed volatile products from the PLA surface were extracted by the vacuum system, part of the equipment used [43], which led to lower-intensity FTIR spectra compared to that of the untreated PLA. Regarding the differences between the treated and untreated PLA, a slight increase in the absorption band in the wavenumber range between 3300 and $3500 \mathrm{~cm}^{-1}$ was noted for the plasma treated samples, which is attributed to $-\mathrm{OH}$ stretching. Plasma treatment promotes an increase in oxygen-containing functional groups, confirming the polar character of the surface already elucidated in the wettability analysis and revealed by Figure 6 [44-46].

Figure 7 shows the FTIR spectra obtained for the corona-treated samples after accelerated weathering. Accelerated weathering deteriorated the structure of the PLA via polymer cleavage, leading to chain scission,

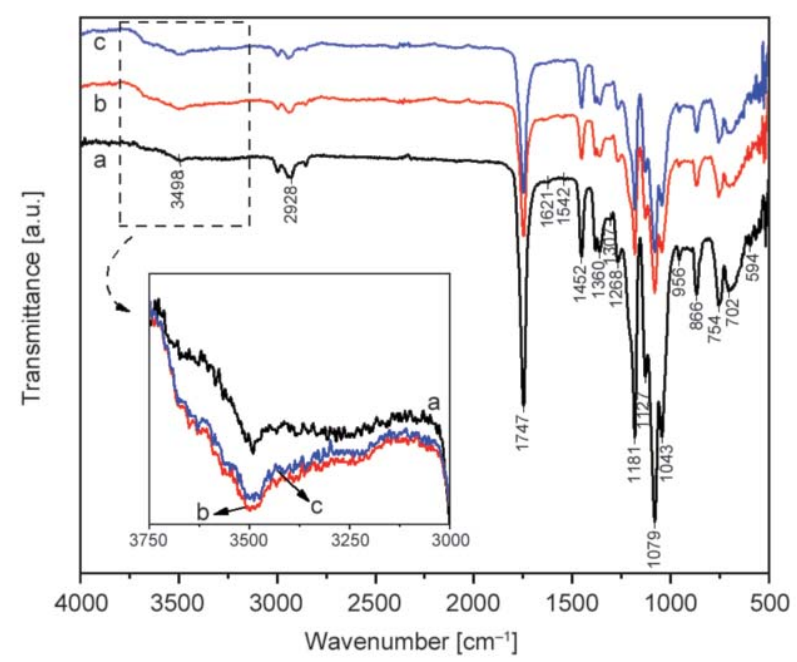

Figure 6. Fourier transform infrared spectroscopy (FTIR) spectra of PLA samples: a) Untreated, b) coronatreated, and c) RF-treated. 


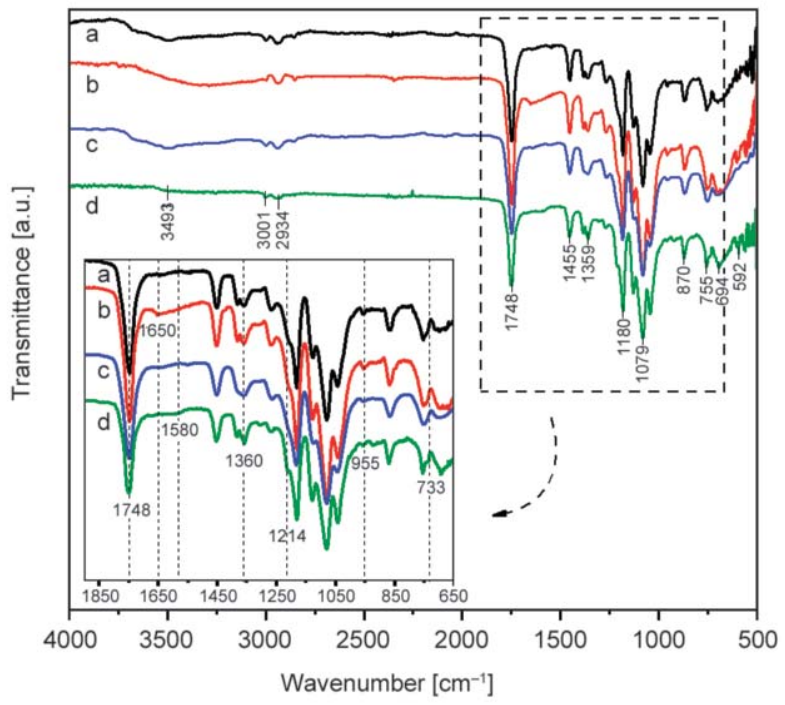

Figure 7. FTIR spectra of corona-treated PLA samples at accelerated weathering times: a) $0 \mathrm{~h}$, b) $500 \mathrm{~h}$, c) $1000 \mathrm{~h}$, and d) $2000 \mathrm{~h}$.

especially at the $\mathrm{C}-\mathrm{O}$ and $\mathrm{C}-\mathrm{C}$ ester bonds from the PLA backbone structure [21]. The formed carboxylic end groups acted as a catalyst for the degradation of PLA $[32,33]$. However, the UV and moisture exposure did not significantly change the chemical structures of the plasma-treated PLA samples. The effect of $2000 \mathrm{~h}$ of weathering exposure in the coronatreated PLA sample is shown in Figure 7 curve d, indicating sharp peaks at 1214 and $1360 \mathrm{~cm}^{-1}$ assigned to $\mathrm{C}-\mathrm{O}-\mathrm{C}$ and $\mathrm{CH}$ and attributed to chain scission of the PLA during degradation. Another interesting result was observed at $957 \mathrm{~cm}^{-1}$, with a peak shift to $955 \mathrm{~cm}^{-1}$ after $2000 \mathrm{~h}$, related to the modification in the amorphous and crystalline structure of the PLA after weathering $[47,48]$. In addition, a new peak at $733 \mathrm{~cm}^{-1}$ appeared in the spectrum of PLA/corona/ $2000 \mathrm{~h}$, while a shoulder appeared at $1650 \mathrm{~cm}^{-1}$ after $1000 \mathrm{~h}$ of weathering. The region at $733-756 \mathrm{~cm}^{-1}$ represents the skeletal vibration of the methylene groups [47], whereas those at $1650 \mathrm{~cm}^{-1}$ reveal the generation of a new $\mathrm{C}=\mathrm{C}$ bond. This proves that the photodegradation via a Norrish II type mechanism occurred during weathering exposure, involving chain cleavage and the presence of newly formed chains $[17,21,41,49,50]$. After $2000 \mathrm{~h}$, this peak was less evident in the PLA/corona samples due to the presence of a new shoulder at lower wavenumbers, i.e., $1580 \mathrm{~cm}^{-1}$. The $1580 \mathrm{~cm}^{-1}$ wavenumber is described as being indicative of water absorption of the material [51]. Apart from the UV irradiation steps, during the accelerated weathering tests, there was also moisture (condensation steps), leading to water absorption

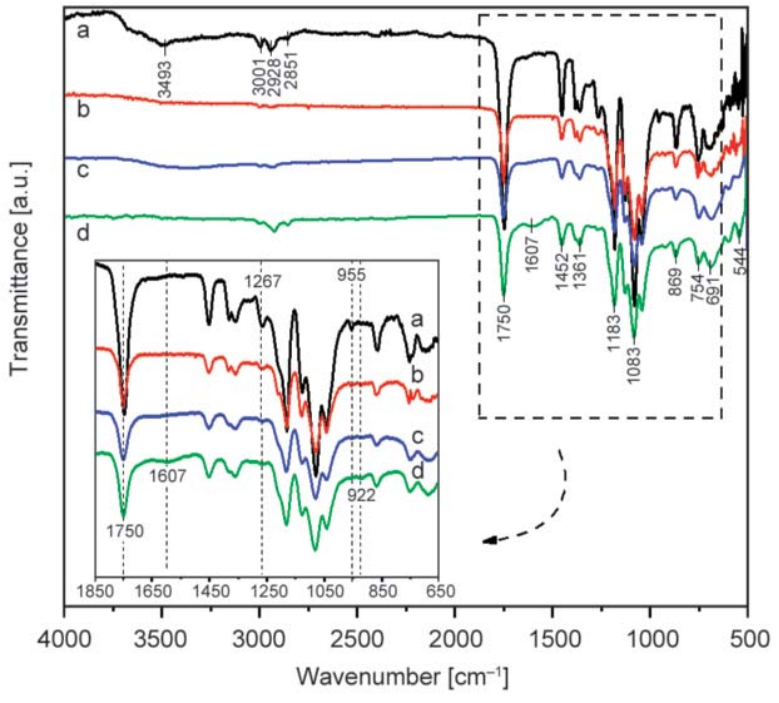

Figure 8. FTIR spectra of the RF-treated PLA samples at accelerated weathering times: a) $0 \mathrm{~h}$, b) $500 \mathrm{~h}$, c) $1000 \mathrm{~h}$, and d) $2000 \mathrm{~h}$.

during the hydrolysis degradation, as confirmed by this peak.

Figure 8 shows the FTIR spectra of the RF-treated PLA samples and the characteristic transmittance peaks after different periods of accelerated weathering. The presence of $\mathrm{C}=\mathrm{C}$ stretching vibration was observed after $2000 \mathrm{~h}$ by a broadening of this band at $1600 \mathrm{~cm}^{-1}$, which could also have combined the observed band at $1580 \mathrm{~cm}^{-1}$ noted in PLA/corona/ $2000 \mathrm{~h}$. The intensity of the ester vibrations observed at 1268 and at $955 \mathrm{~cm}^{-1}$ simultaneously decrease. In addition, a new peak seemed to appear at $922 \mathrm{~cm}^{-1}$ for PLA/RF/500h and PLA/RF/2000h. Previous authors have generally described this shift in the spectral region between 950 and $920 \mathrm{~cm}^{-1}$ as indicative of the crystallization event of PLA, characteristic of $\alpha$ crystals $[21,48]$.

\subsection{Molecular weight analysis (GPC/SEC)}

GPC/SEC was performed to analyze the changes in the molecular weight distribution of the plasma-treated PLA samples exposed to accelerated weathering conditions, and to evaluate the resultant chain scission of the polymer. Table 1 shows the changes in the average molecular number $\left(M_{\mathrm{n}}\right)$ and weight $\left(M_{\mathrm{w}}\right)$ of the plasma-treated PLA as a function of accelerated weathering time and also reports the percentage of degradation and the polydispersity index $\left(\bigoplus_{\mathrm{M}}\right)$.

In agreement with prior works, it is necessary to mention that PLA suffered molecular scission during the fabrication of the samples at high temperatures $[52,53]$. Before sample preparation, the raw material, 
Table 1. Molecular weights and polydispersity index $\left(\bigoplus_{M}\right)$ of the PLA samples.

\begin{tabular}{|l|c|c|c|c|c|c|c|}
\hline \multicolumn{1}{|c|}{ Sample } & $\begin{array}{c}\boldsymbol{M}_{\mathbf{n}} \\
{\left[\mathbf{g} \cdot \mathbf{m o l}^{-\mathbf{1}} \mathbf{l}\right.}\end{array}$ & $\begin{array}{c}\boldsymbol{M}_{\mathbf{n}} \text { degradation } \\
{[\mathbf{\%}]}\end{array}$ & $\begin{array}{c}\boldsymbol{M}_{\mathbf{n}} \text { cumulative } \\
\mathbf{d e g r a d a t i o n} \\
{[\mathbf{\%}]}\end{array}$ & $\begin{array}{c}\boldsymbol{M}_{\mathbf{w}} \\
{\left[\mathbf{g} \cdot \mathbf{m o l}^{-\mathbf{1}} \mathbf{]}\right.}\end{array}$ & $\begin{array}{c}\boldsymbol{M}_{\mathbf{w}} \text { degradation } \\
{[\mathbf{\%}]}\end{array}$ & $\begin{array}{c}\boldsymbol{M}_{\mathbf{w}} \text { cumulative } \\
\mathbf{d e g r a d a t i o n} \\
{[\mathbf{\%}]}\end{array}$ & $\boldsymbol{D}_{\mathbf{M}}$ \\
\hline Untreated PLA/0h & 71500 & - & - & 89500 & - & - & 1.3 \\
\hline PLA/corona/0h & 13290 & - & - & 17420 & - & - & 1.3 \\
\hline PLA/corona/500h & 11340 & 15 & 15 & 15180 & 13 & 13 & 1.3 \\
\hline PLA/corona/1000h & 5305 & 53 & 60 & 7446 & 51 & 57 & 1.4 \\
\hline PLA/corona/2000h & 2085 & 61 & 84 & 2899 & 61 & 83 & 1.4 \\
\hline PLA/RF/0 h & 33680 & - & - & 44090 & - & - & 1.3 \\
\hline PLA/RF/500h & 18350 & 46 & 46 & 23950 & 46 & 46 & 1.3 \\
\hline PLA/RF/1000h & 7226 & 61 & 79 & 9770 & 59 & 78 & 1.4 \\
\hline PLA/RF/2000h & 1731 & 76 & 95 & 2444 & 75 & 94 & 1.4 \\
\hline
\end{tabular}

$M_{\mathrm{n}}$ : average molecular number; $M_{\mathrm{w}}$ : average molecular weight.

i.e., PLA 2003D, showed an average molecular number $\left(M_{\mathrm{n}}\right)$ of $100422 \mathrm{~g} \cdot \mathrm{mol}^{-1}$, an average molecular weight $\left(M_{\mathrm{w}}\right)$ of $180,477 \mathrm{~g} \cdot \mathrm{mol}^{-1}$, and a polydispersity index of 1.79 [54]. A large difference was observed after sample preparation, with the $M_{\mathrm{n}}$ and $M_{\mathrm{w}}$ of neat PLA after sample production being 71500 and $89500 \mathrm{~g} \cdot \mathrm{mol}^{-1}$, respectively, while its $\bigoplus_{\mathrm{M}}$ was 1.3. Furthermore, differences were found in the $M_{\mathrm{n}}$ and $M_{\mathrm{w}}$ for PLA/corona/0h and PLA/RF/0h. Since the sheet production was exactly the same way for corona- and RF-treated samples, these results should be related to each type of plasma used. The kinetic energy of the plasma reactive species during the application of this treatment caused slight surface heating [43]. It is also mentioned that uncontrolled and high-energy plasma often break up both the $\mathrm{C}-\mathrm{H}$ and $\mathrm{C}-\mathrm{C}$ bonds simultaneously, leading to the degradation of the polymer backbone [42]. It is clear that the $M_{\mathrm{w}}$ and $M_{\mathrm{n}}$ of both the plasma-treated PLA samples gradually decreased after weathering, indicating the chain cleavage already mentioned, but with different kinetics were noted. While the corona treatment showed the highest reduction of $M_{\mathrm{w}}$ and $M_{\mathrm{n}}$ between 500 and $1000 \mathrm{~h}$ of weathering exposure, the PLA samples treated by RF plasma showed the same percentage of decrease after $500 \mathrm{~h}$ of degradation, i.e., a reduction of $46 \%$. Although the PLA/RF samples started the weathering cycles with a higher molecular weight value, after $2000 \mathrm{~h}$, a lower $M_{\mathrm{w}}$ than that of PLA/corona was found. In the case of the corona-treated PLA, the $M_{\mathrm{w}}$ decreased from 13290 to $2085 \mathrm{~g} \cdot \mathrm{mol}^{-1}$ after $2000 \mathrm{~h}$ of accelerated weathering, while the initial Mn of the RF-treated PLA showed a higher decrease from 33680 to $1731 \mathrm{~g} \cdot \mathrm{mol}^{-1}$ after $2000 \mathrm{~h}$ under the same conditions. A similar trend of degradation was observed for the untreated PLA
[21]. A 91\% degradation of the untreated PLA, corresponding to an $M_{\mathrm{n}}$ of $6500 \mathrm{~g} \cdot \mathrm{mol}^{-1}$ and an $M_{\mathrm{w}}$ of $9000 \mathrm{~g} \cdot \mathrm{mol}^{-1}$, was achieved after $2000 \mathrm{~h}$ of aging, whereas approximately $95 \%$ was noted for PLA/RF/ $2000 \mathrm{~h}$. This confirms our previous conclusions that $\mathrm{RF}$ treatment promoted the weathering degradation of PLA more than corona treatment. Another interesting result is the constant similar $\bigoplus_{\mathrm{M}}$ of the PLA treated with corona and RF during the weathering exposure, which means that the chain scissions randomly occurred in all molecules of the PLA [52, 53].

\subsection{Thermal properties}

DSC was used to determine the changes in the degree of crystallinity characterized by enthalpy and melting phenomena of the plasma-treated PLA samples before and after 500,1000, and $2000 \mathrm{~h}$ of accelerated weathering. Figure 9 shows the DSC curves of the corona- and RF-treated PLA from the first heating scan. The results are summarized in Table 2.

The behavior of both plasma-treated PLA samples could be considered analogous before weathering, but slight differences were noted compared to untreated PLA. The glass transition and melting temperatures increased to 59 and $150^{\circ} \mathrm{C}$, respectively, after plasma treatment, while the amorphous character remained the same after corona and RF treatment. In addition, the cold-crystallization temperature was observed to be higher for the corona-treated sample $\left(123^{\circ} \mathrm{C}\right)$, while the RF-treated sample seemed to present two exothermic events (at 93 and $127^{\circ} \mathrm{C}$ ). During the plasma surface treatment, $\mathrm{H}$ atoms were extracted from the $\mathrm{C}-\mathrm{H}$ bonds of the polymer chains, generating carbon radicals able for a crosslinking formation in the PLA surface $[42,55,56]$, which restricted the chain mobility of PLA. This explains the 

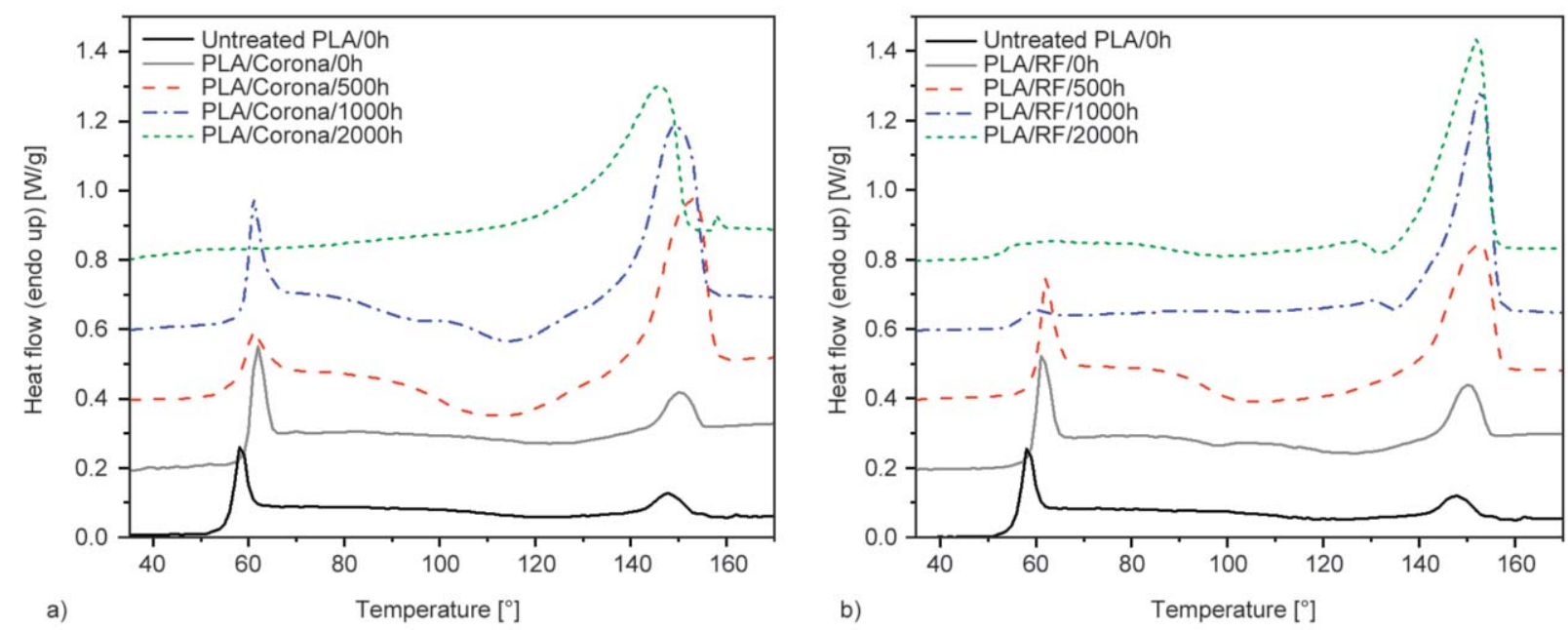

Figure 9. Differential scanning calorimetry (DSC) first heating curves of PLA samples treated by: a) corona plasma and b) RF plasma.

observed shift of $T_{\mathrm{g}}$ and $T_{\mathrm{m}}$ to higher temperatures after plasma treatment.

As the weathering time increased, the corona- and RF-treated PLA samples showed differences between their cold crystallization and melting enthalpies. These values indicate that the noted crystallinity in the treated PLA samples already occurred before DSC analysis due to the weathering process, especially for long weathering times, which is in agreement with the XRD analysis. After $2000 \mathrm{~h}$ of weathering, the corona-treated sample showed the absence of cold crystallization, also not seen in PLA/ $\mathrm{RF} / 1000 \mathrm{~h}$, which means a complete semicrystalline character of the plasma-treated PLA after accelerated weathering.

The effect of the accelerated weathering exposure was also reflected in the glass transition of the samples. An interesting result was observed for the glass transition of PLA/corona/500h, which is similar to neat PLA as noted in our previous work [21]. The erosion process that occurs during weathering and the degradation process itself should be enough to degrade the lightly crosslinked structure created on the PLA surface during the plasma treatment. After $1000 \mathrm{~h}$, small crystallites formed during UV-initiated degradation acted as physical crosslink points, which restrained the chain movement of the corona-treated PLA, so that higher $T_{\mathrm{g}}$ temperatures were noted and the amorphous chains became less mobile [21, 57]. After $2000 \mathrm{~h}$ of weathering, PLA/corona/2000h presented a high degree of crystallinity, reflecting the very low molecular weight of the plasma treated PLA due to the high level of degradation. $T_{\mathrm{g}}$ was almost imperceptible and showed the lowest value of all the samples, whereas untreated PLA showed the same $T_{\mathrm{g}}$ after $2000 \mathrm{~h}$ of aging [21].

An increasing accelerated weathering time showed that the $T_{\mathrm{m}}$ of the corona-treated PLA decreased. The respective peaks were more pronounced and broadened over time, reflected in the melting enthalpy and the increased degree of crystalline for long weathering periods. However, an exception was observed for

Table 2. Characteristic temperatures, enthalpies, and degree of crystallization of the PLA samples.

\begin{tabular}{|l|c|c|c|c|c|c|c|}
\hline \multicolumn{1}{|c|}{ Sample } & $\begin{array}{c}\boldsymbol{T}_{\mathbf{g}} \\
{\left[{ }^{\circ} \mathbf{C}\right]}\end{array}$ & $\begin{array}{c}\Delta \boldsymbol{H}_{\mathbf{m}} \\
{\left[\mathbf{J}^{-\mathbf{g}}\right]}\end{array}$ & $\begin{array}{c}\boldsymbol{T}_{\mathbf{m} 1} \\
{\left[{ }^{\circ} \mathbf{C}\right]}\end{array}$ & $\begin{array}{c}\boldsymbol{T}_{\mathbf{m} 2} \\
{\left[{ }^{\circ} \mathbf{C}\right]}\end{array}$ & $\begin{array}{c}\Delta \boldsymbol{H}_{\mathbf{C C}} \\
{\left[\mathbf{J}^{-1} \mathbf{g}^{-1}\right]}\end{array}$ & $\begin{array}{c}\boldsymbol{T}_{\mathbf{C C}} \\
{\left[{ }^{\circ} \mathbf{C}\right]}\end{array}$ & $\begin{array}{c}\boldsymbol{X}_{\mathbf{c}} \\
{[\%]}\end{array}$ \\
\hline Untreated PLA/0h & 56.9 & 2.3 & & 147.7 & 2.2 & 121.2 & 0 \\
\hline PLA/corona/0h & 59.2 & 4.0 & & 150.4 & 5.2 & 123.3 & 0 \\
\hline PLA/corona/500h & 56.5 & 23.9 & & 153.5 & 13.4 & 113.5 & 11.2 \\
\hline PLA/corona/1000h & 58.7 & 31.8 & & 149.2 & 17.6 & $93.2 / 116.0$ & 15.3 \\
\hline PLA/corona/2000h & 45.7 & 32.6 & & 145.8 & 0.0 & - & 34.8 \\
\hline PLA/RF/0h & 58.7 & 5.1 & & 150.3 & 7.3 & $97.2 / 126.5$ & 0 \\
\hline PLA/RF/500h & 59.2 & 21.6 & & 152.8 & 9.0 & 102.2 & 13.4 \\
\hline PLA/RF/1000h & 56.5 & 33.6 & 130.7 & 153.1 & 0.0 & 136.7 & 35.9 \\
\hline PLA/RF/2000h & 53.1 & 38.3 & 126.6 & 152.3 & 3.0 & 99.3 & 37.7 \\
\hline
\end{tabular}


PLA/corona/1000h, which did not correspond to this trend. It was observed that shorter chains formed after chain scission by photo and hydrolysis degradation, causing inconsistent changes in the glass and melting temperature with increasing weathering time. A complex influence of factors such as changes in free volume and the configuration of the amorphous phase could also support our observed results $[2,21$, 49, 58-63].

The melting temperature of the PLA samples treated by RF showed the opposite trend as the corona-treated samples. A slight increase of $3^{\circ} \mathrm{C}$ was noticed after $500 \mathrm{~h}$ of UV and moisture exposure, which remained almost constant with increasing weathering time. In addition, a new endothermic event was observed for PLA/RF/1000h and PLA/RF/2000h around 131 and $127^{\circ} \mathrm{C}$, respectively. This behavior was also observed for the untreated PLA after $2000 \mathrm{~h}$ of weathering exposure [21]. The double-peak could be the result of the melting of different sized lamellae formed during the degradation process or the result of a melting-recrystallization-melting process [19, 64-66]. Since cold crystallization was not observed after these periods, the latter explanation is the most obvious.

The $T_{\mathrm{g}}$ of the PLA treated by RF plasma remained the same at $59{ }^{\circ} \mathrm{C}$ after the first period of weathering, but decreased as the weathering time increased to 1000 and $2000 \mathrm{~h}$, while the degree of crystallinity increased over the entire weathering time. The shorter chains from polymer cleavage during UV and hydrolysis degradation had lower molecular weight and higher mobility. Thus, the observed lower $T_{\mathrm{g}}$ and the ability to re-organize and create crystalline domains is prevalent for enhancing the stiffness of the samples.

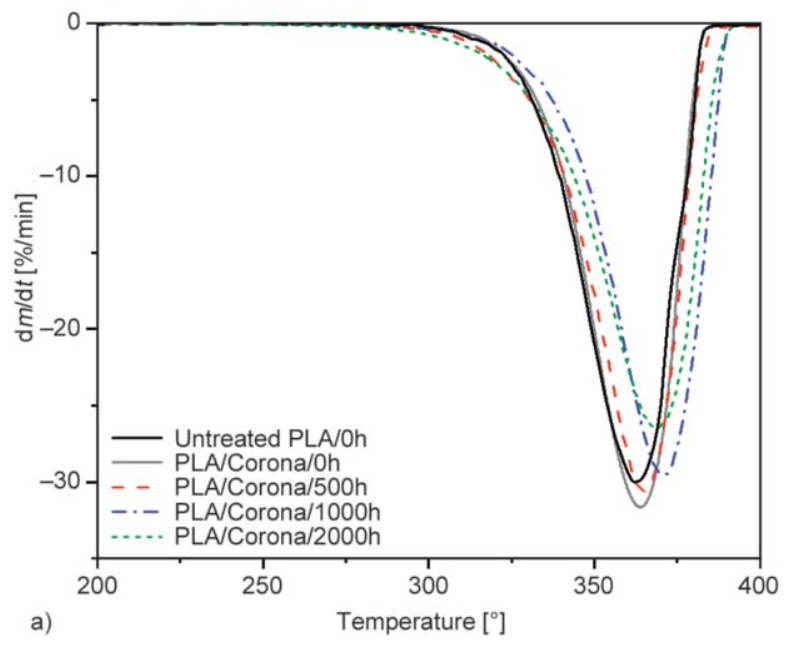

However, due to the advanced polymer degradation, this semicrystalline structure was no more efficient for physically restricting the amorphous polymer chains, as was also observed in the corona samples (i.e., a decrease in $T_{\mathrm{g}}$ ).

Concerning the untreated PLA from our previous study [21], after $2000 \mathrm{~h}$ of weathering, it presented similar characteristics to the plasma-treated samples after $500 \mathrm{~h}$, such as cold crystallization, glass transition, and double melting temperature, and, most importantly, it achieved a degree of crystallization of approximately $10 \%$. These results are in accordance with most of the other results, showing that plasma treatment accelerated the weathering degradation of PLA. In addition, it appears that the RF treatment promoted the UV- and moisture-initiated degradation of PLA much more than observed in the corona-treated samples, as was already confirmed by other analyses.

\subsection{Thermogravimetric analysis}

The thermal stability information of the plasmatreated PLA was obtained by TGA. The differential TGA curves for the corona- and RF-treated PLA samples after different periods of accelerated weathering are shown in Figure 10. Table 3 shows the decomposition temperature at 5 and $50 \%$ of mass loss, as well the dTGA peak maximum temperatures observed for all samples.

Both plasma-treated samples display a one-step mass loss from approximately 300 to $400{ }^{\circ} \mathrm{C}$, and no differences in the thermal degradation were detected between the neat PLA [21] and the corona-treated PLA in that range before accelerated weathering degradation. However, a higher onset was found for the

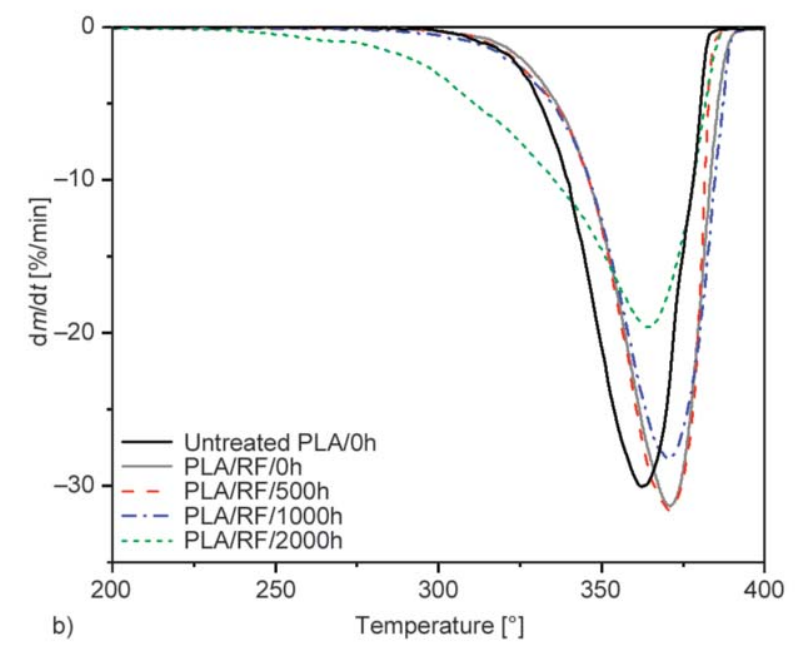

Figure 10. Differential TGA curves of the PLA samples treated by: a) corona plasma and b) RF plasma. 
Table 3. Characteristic degradation temperatures of the PLA samples.

\begin{tabular}{|l|c|c|c|}
\hline \multicolumn{1}{|c|}{ Sample } & $\begin{array}{l}\boldsymbol{T}_{\mathbf{5 \%}} \\
{\left[{ }^{\circ} \mathbf{C}\right]}\end{array}$ & $\begin{array}{l}\boldsymbol{T}_{\mathbf{5 0} \%} \\
{\left[{ }^{\circ} \mathbf{C}\right]}\end{array}$ & $\begin{array}{l}\boldsymbol{T}_{\max } \\
{\left[{ }^{\circ} \mathbf{C}\right]}\end{array}$ \\
\hline Untreated PLA/0h & 332 & 359 & 362 \\
\hline PLA/corona/0h & 332 & 360 & 364 \\
\hline PLA/corona/500h & 326 & 360 & 365 \\
\hline PLA/corona/1000h & 331 & 366 & 371 \\
\hline PLA/corona/2000h & 323 & 362 & 369 \\
\hline PLA/RF/0h & 334 & 366 & 371 \\
\hline PLA/RF/500h & 331 & 365 & 371 \\
\hline PLA/RF/1000h & 326 & 365 & 371 \\
\hline
\end{tabular}

thermal degradation of the PLA treated by RF plasma before weathering degradation. Since both plasma-treated PLA samples showed an amorphous character before UV and moisture exposure in the XRD and DSC analyses, the observed event suggests some crosslinking of the RF-treated PLA [43, 67]. Thus, the energy required for the thermal degradation increased as the length and stability of the chains increased, in agreement with the GPC/SEC results.

The TGA traces revealed that the thermodegradation of the corona-treated samples proceeded at lower temperatures than the RF-treated samples. However, as the degradation exposure time increased, the temperature at $50 \%$ mass loss also increased. It is known that during weathering exposure, polymer chains are cleaved and are able to re-organize into crystalline regions, thereby converting the amorphous character of PLA into semicrystalline, as was shown in the XRD and DSC results. Another interesting result was observed in the gradual increase of $T_{5 \%}$, which followed the degree of crystallinity of the samples up to $35 \%$, i.e., the degree of crystallinity observed in $\mathrm{DSC}$ for PLA/corona/500h $<\mathrm{PLA} / \mathrm{RF} / 500 \mathrm{~h}<\mathrm{PLA} /$ corona $/ 1000 \mathrm{~h}<\mathrm{PLA} /$ corona $/ 2000 \mathrm{~h}$ and the $T_{5 \%}$ showed exactly the same trend. After achieving 36\% of crystallinity in the DSC in PLA/RF/1000h, the $T_{5 \%}$ started to decrease gradually.

Since PLA is an amorphous polymer and the observed semicrystalline structure was achieved by the degradation of its chains after UV and moisture attacks and chain scission, the results suggest that after $35 \%$ of crystallinity, PLA treated by RF plasma forms numerous shorter chain segments, for which lower energy is required for thermal degradation, as seen in Table 3. These results are also consistent with the observed values after $2000 \mathrm{~h}$ of accelerated weathering. An interesting observation was that when comparing the plasma-treated samples with the untreated
PLA after $2000 \mathrm{~h}$ of weathering exposure time, only the $T_{5 \%}$ showed a significant reduction to $317^{\circ} \mathrm{C}$, while $T_{50 \%}\left(356^{\circ} \mathrm{C}\right)$ and $T_{\max }\left(364^{\circ} \mathrm{C}\right)$ remained almost identical as for the untreated PLA/0h sample [21]. These results corroborate our previous discussion showing that a decrease in $T_{5 \%}$ represents some shorter chains for $2000 \mathrm{~h}$ of aging, which is much lower than noted for the plasma-treated samples.

\subsection{Mechanical properties}

The AM-FM AFM technique was employed to analyze the mechanical properties of the untreated and plasma-treated PLA samples in the top surface area, allowing to obtain images of the Young's modulus distribution. The AM-FM AFM images of the untreated and plasma-treated PLA samples before and after accelerated aging are shown in Figure 11. Moreover, the mean values of the Young's modulus evaluated by Gaussian fitting are presented in the related histograms and the values are summarized in Table 4. Changes in the mechanical properties of the bulk of the samples treated by plasma were measured by stress-strain tests, and they are discussed later.

The Young's modulus of the untreated PLA sample achieved a value of $2.2 \mathrm{GPa}$. The plasma treatment noticeably increased the mechanical properties of the PLA samples as a result of a combination of different processes, such as ablation, etching, functionalization, and crosslinking processes in the few tens of nanometers in the surface area $[68,69]$. The Young's modulus increased to $2.9 \mathrm{GPa}$ for the PLA/corona/ $0 \mathrm{~h}$ sample. In the case of RF treatment, Young's modulus of the PLA/RF/0h sample increased even more, achieving a value of $8.3 \mathrm{GPa}$. The accelerated weathering aging resulted in mechanical property changes because of a combination of UV, thermal, and hydrolytic degradation. A time of $500 \mathrm{~h}$ of aging led to an improvement in the mechanical properties of the untreated and corona-treated PLA samples as postprocessing chemical reactions, while Young's modulus was 3.3 and $8.3 \mathrm{GPa}$, respectively. On the contrary, the mechanical properties of the RF-treated PLA slightly deteriorated, while Young's modulus decreased to $8.1 \mathrm{GPa}$. The additional increase in aging time was responsible for increasing Young's modulus for the untreated PLA, while the highest value was achieved after $2000 \mathrm{~h}$ of aging $(6.2 \mathrm{GPa})$. In contrast, $1000 \mathrm{~h}$ of aging of the plasma-treated PLA samples led to a decrease in Young's modulus, 

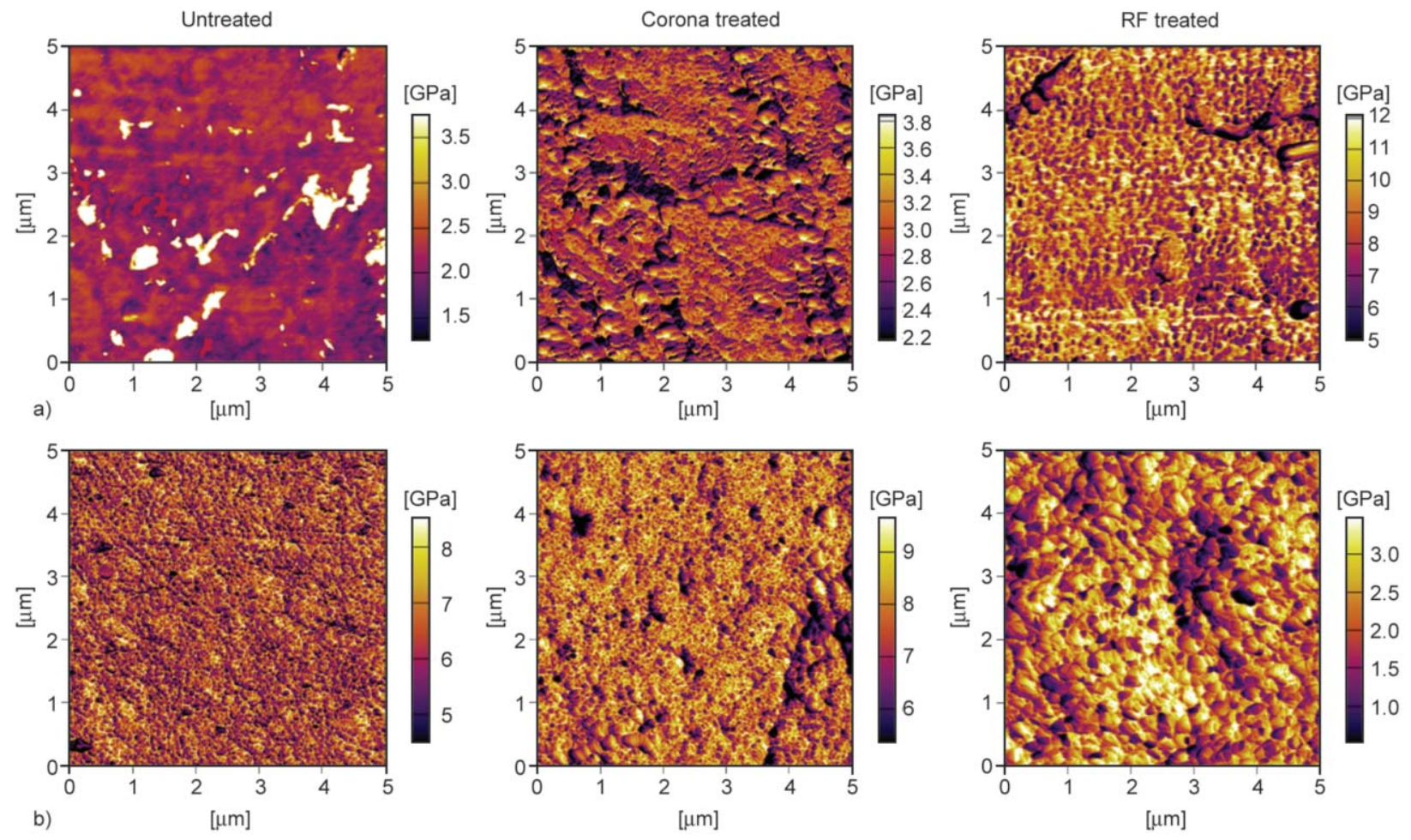

Figure 11. Extended AC mode amplitude modulation-frequency modulation technique (AM-AFM) images of PLA samples (from left to right: Untreated, corona-, and RF-treated) at accelerated weathering times: a) $0 \mathrm{~h}$ and b) $2000 \mathrm{~h}$.

achieving values of 8.3. and 3.4 GPa for the corona and RF plasma treatments, respectively. The additional increase in aging time resulted in a further decrease of Young's modulus values to 7.7 and $2.1 \mathrm{GPa}$ for the PLA/corona/2000h and PLA/RF/2000h samples, respectively. This confirms the enhanced degradation of the plasma-treated PLA samples caused by the incorporated polar functional groups responsible for catalytic hydrolytic degradation, together with thermal and UV degradation, which was pronounced after longer aging times.

Table 4. Surface mechanical properties of the PLA samples.

\begin{tabular}{|l|c|c|}
\hline \multirow{2}{*}{\multicolumn{1}{|c|}{ Sample }} & \multicolumn{2}{|c|}{$\begin{array}{c}\text { Young's modulus } \\
\text { [GPa] }\end{array}$} \\
\cline { 2 - 3 } & Mean & Width \\
\hline PLA/0h & 2.2 & 0.2 \\
\hline PLA/500h & 3.3 & 0.2 \\
\hline PLA/1000h & 3.7 & 0.5 \\
\hline PLA/2000h & 6.2 & 1.0 \\
\hline PLA/corona/0h & 2.9 & 0.3 \\
\hline PLA/corona/500h & 8.3 & 1.2 \\
\hline PLA/corona/1000h & 8.3 & 1.2 \\
\hline PLA/corona/2000h & 7.7 & 1.0 \\
\hline PLA/RF/0h & 8.6 & 1.6 \\
\hline PLA/RF/500h & 8.1 & 1.3 \\
\hline PLA/RF/1000h & 3.4 & 0.3 \\
\hline PLA/RF/2000h & 2.1 & 0.8 \\
\hline
\end{tabular}

The bulk changes in the mechanical properties of the PLA samples were evaluated by stress-strain tests, and the mechanical properties are summarized in Table 5. The mechanical properties of the neat PLA and the PLA samples treated with corona and RF plasma were similar, since this treatment affected only the surface area (few tens of nanometers) [22], and thus the bulk was not affected before weathering exposure.

It is seen in Table 5 that during the initial accelerated weathering period of $500 \mathrm{~h}$, the tensile strength, tensile strain and toughness of the corona treated PLA samples decreased. During this short period of weathering exposure, chain cleavage of the PLA occurred but was not enough to allow the rearrangement of polymer chains into a strong and stable crystalline structure. As shown in the DSC analysis, the crystallinity degree was low and not detectable by XRD analysis. Slight differences were found in PLA/coro$\mathrm{na} / 1000 \mathrm{~h}$ for Young's modulus, but they were significant, showing higher values for all mechanical properties than the shorter period of aging. This happened due to the self-organization of small chains into crystalline domains. This increase was revealed for $15 \%$ of crystallinity, achieved due to a longer period of UV and moisture exposure. The chain scission effect was found to be more dominant in this period, corroborating the GPC analysis. 
Table 5. Mechanical properties of PLA samples.

\begin{tabular}{|l|c|c|c|c|}
\hline \multicolumn{1}{|c|}{ Sample } & $\begin{array}{c}\text { Stress at break } \\
{[\mathbf{M P a}]}\end{array}$ & $\begin{array}{c}\text { Strain at break } \\
{[\mathbf{\%}]}\end{array}$ & $\begin{array}{c}\text { Young's modulus } \\
{[\mathbf{M P a}]}\end{array}$ & $\begin{array}{c}\text { Toughness } \\
{[\mathbf{M P a} \% \mathbf{]}}\end{array}$ \\
\hline Untreated PLA/0h & $25.5 \pm 1.2$ & $1.8 \pm 0.4$ & $3036 \pm 101$ & $35.4 \pm 10.1$ \\
\hline PLA/corona/0h & $24.3 \pm 2.3$ & $1.5 \pm 0.1$ & $2760 \pm 240$ & $25.2 \pm 4.2$ \\
\hline PLA/corona/500h & $6.6 \pm 7.7$ & $1.6 \pm 0.3$ & $2288 \pm 92$ & $20.0 \pm 9.3$ \\
\hline PLA/corona/1000h & $38.9 \pm 5.1$ & $2.1 \pm 0.4$ & $2362 \pm 330$ & $41.2 \pm 10.0$ \\
\hline PLA/corona/2000h & - & - & - & - \\
\hline PLA/RF/0h & $24.5 \pm 2.0$ & $1.6 \pm 0.4$ & $2839 \pm 170$ & $27.1 \pm 12.2$ \\
\hline PLA/RF/500h & $46.0 \pm 8.1$ & $2.5 \pm 0.5$ & $1823 \pm 269$ & $57.1 \pm 19.5$ \\
\hline PLA/RF/1000h & $27.3 \pm 2.5$ & $1.5 \pm 0.2$ & $1754 \pm 346$ & $19.3 \pm 3.7$ \\
\hline PLA/RF/2000h & - & - & - & - \\
\hline
\end{tabular}

The same was observed for PLA/RF/500h, where Table 5 shows an increase in stress and strain at break, but a decrease in Young's modulus and an increase in the toughness. The crystallinity degree of this sample, i.e., $13 \%$, which is between $11 \%$ and $15 \%$ for PLA/corona/500h and PLA/corona/1000h, reveals an interesting gradual decrease of Young's modulus following the gradual increase observed in the crystallinity, at least up to $15 \%$, as observed in Figure 12. As is known, crystallinity increases as a result of chain scission, so Young's modulus and strength may be expected to increase during degradation. However, this effect is offset by the fact that as the crystallinity increases, the molecular weight decreases [70], as noted in the GPC results. Consequently, it reduces the values of strength and Young's modulus, as noted in Figure 12 and Table 5. A larger increase in the crystallinity was found for PLA/RF/ 1000 h, i.e., approximately $35 \%$, following a drop in the molecular weight, which can explain why the mechanical properties reduced for the crystalline sample.

It should be pointed out that the PLA/corona/2000h and PLA/RF/2000h samples were not tested because they were significantly brittle due to the degradation

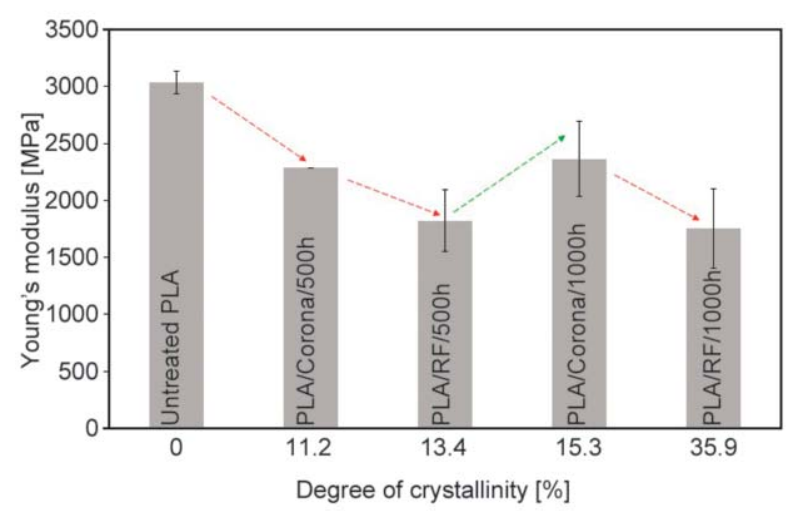

Figure 12. Young's modulus $v s$. degree of crystallinity of PLA samples. of the polymer chains, which is visible in the SEM images in Figure 2. On the contrary, the physical integrity of the untreated PLA/2000h was still observed with $12.3 \pm 4.8 \mathrm{MPa}$ of stress at break and Young's modulus of $1748 \pm 431$.

\section{Conclusions}

Low-temperature plasma treatment was used to enhance the degradation of PLA. For this purpose, corona and RF plasma treatments with subsequent accelerated weathering aging up to $2000 \mathrm{~h}$ were employed. It was observed that plasma treatment led to a significant acceleration of the weathering degradation of PLA, combining thermal, UV, and hydrolytic degradation processes. This was mainly caused by the formation of hydroxyl end groups resulting in catalytic degradation of PLA . Moreover, increased hydrophilicity after plasma treatment, and therefore water uptake, was responsible for enhanced hydrolytic degradation. Consequently the overall bulk mechanical properties of plasma-treated PLA gradually decreased in the molecular weights and the polymer chains were ordered into crystalline regions, changing the amorphous character of PLA to a semicrystalline structure. The RF treatment showed to be more efficient than the corona treatment after $2000 \mathrm{~h}$ of weathering, representing a suitable candidate for applications requiring enhanced degradation of PLA.

\section{Acknowledgements}

This publication was supported by the Qatar University Collaborative Grant No. QUCG-CAM 19/20-3 and QUCG-CAM20/21-3. The findings achieved herein are solely the responsibility of the authors. The authors thank Prof. Sergei Nazarenko, University of Southern Mississippi, United States, and his group for their help in conducting the GPC analysis, with special thanks to Ms. Karina Reynolds for her efforts in running the samples. SEM analysis was accomplished in the Central Laboratories unit, Qatar University. 


\section{References}

[1] Avella M., Buzarovska A., Errico M. E., Gentile G., Grozdanov A.: Eco-challenges of bio-based polymer composites. Materials, 2, 911-925 (2009).

https://doi.org/10.3390/ma2030911

[2] Buzarovska A., Grozdanov A.: Biodegradable poly(Llactic acid) $/ \mathrm{TiO}_{2}$ nanocomposites: Thermal properties and degradation. Journal of Applied Polymer Science, 123, 2187-2193 (2012).

https://doi.org/10.1002/app.34729

[3] Ikada Y., Tsuji H.: Biodegradable polyesters for medical and ecological applications. Macromolecular Rapid Communications, 21, 117-132 (2000).

https://doi.org/10.1002/(sici)15213927(20000201)21:3<117::aid-marc117>3.3.co;2-0

[4] Gasmi S., Hassan M. K., Luyt A. S.: Crystallization and dielectric behavior of PLA and PHBV in PLA/PHBV blends and $\mathrm{PLA} / \mathrm{PHBV} / \mathrm{TiO}_{2}$ nanocomposites. Express Polymer Letters, 13, 199-212 (2019).

https://doi.org/10.3144/expresspolymlett.2019.16

[5] Weir N. A., Buchanan F. J., Orr J. F., Farrar D. F., Dickson G. R.: Degradation of poly-L-lactide. Part 2: Increased temperature accelerated degradation. Proceedings of the Institution of Mechanical Engineers Part H: Journal of Engineering in Medicine, 218, 321-330 (2004).

https://doi.org/10.1243/0954411041932809

[6] Mofokeng J. P., Luyt A. S.: Dynamic mechanical properties of PLA/PHBV, PLA/PCL, PHBV/PCL blends and their nanocomposites with $\mathrm{TiO} 2$ as nanofiller. Thermochimica Acta, 613, 41-53 (2015).

https://doi.org/10.1016/j.tca.2015.05.019

[7] Luyt A. S., Gasmi S.: Influence of blending and blend morphology on the thermal properties and crystallization behaviour of PLA and PCL in PLA/PCL blends. Journal of Materials Science, 51, 4670-4681 (2016). https://doi.org/10.1007/s10853-016-9784-Z

[8] Zhuang W., Liu J., Zhang J. H., Hu B. X., Shen J.: Preparation, characterization, and properties of $\mathrm{TiO}_{2} /$ PLA nanocomposites by in situ polymerization. Polymer Composites, 30, 1075-1080 (2008).

https://doi.org/10.1002/pc.20658

[9] Woodruff M. A., Hutmacher D. W.: The return of a forgotten polymer - Polycaprolactone in the $21^{\text {st }}$ century. Progress in Polymer Science, 35, 1217-1256 (2010). https://doi.org/10.1016/j.progpolymsci.2010.04.002

[10] Mofokeng J. P., Luyt A. S.: Morphology and thermal degradation studies of melt-mixed PLA/PHBV biodegradable polymer blend nanocomposites with $\mathrm{TiO}_{2}$ as filler. Journal of Applied Polymer Science, 132, 42138/1-42138/11 (2015).

https://doi.org/10.1002/app.42138

[11] Shogren R. L., Doane W. M., Garlotta D., Lawton J. W., Willett J. L.: Biodegradation of starch/polylactic acid/ poly(hydroxyester-ether) composite bars in soil. Polymer Degradation and Stability, 79, 405-411 (2003). https://doi.org/10.1016/S0141-3910(02)00356-7
[12] Qi X., Ren Y., Wang X.: New advances in the biodegradation of poly(lactic) acid. International Biodeterioration and Biodegradation, 117, 215-223 (2017).

https://doi.org/10.1016/j.ibiod.2017.01.010

[13] Anžlovar A., Kržan A., Žagar E.: Degradation of PLA/ $\mathrm{ZnO}$ and $\mathrm{PHBV} / \mathrm{ZnO}$ composites prepared by melt processing. Arabian Journal of Chemistry, 11, 343-352 (2018). https://doi.org/10.1016/j.arabjc.2017.07.001

[14] Jo M-Y., Ryu Y. J., Ko J. H., Yoon J-S.: Hydrolysis and thermal degradation of poly(L-lactide) in the presence of talc and modified talc. Journal of Applied Polymer Science, 129, 1019-1025 (2013).

https://doi.org/10.1002/app.38753

[15] Copinet A., Bertrand C., Longieras A., Coma V., Couturier Y.: Photodegradation and biodegradation study of a starch and poly(lactic acid) coextruded material. Journal of Polymers and the Environment, 11, 169-179 (2003).

https://doi.org/10.1023/A:1026056415604

[16] Marra A., Cimmino S., Silvestre C.: Effect of $\mathrm{TiO}_{2}$ and $\mathrm{ZnO}$ on PLA degradation in various media. Advanced Materials Science Research, 2, 1-8 (2017).

https://doi.org/10.15761/AMS.1000122

[17] Kaynak C., Sari B.: Accelerated weathering performance of polylactide and its montmorillonite nanocomposite. Applied Clay Science, 121-122, 86-94 (2016). https://doi.org/10.1016/j.clay.2015.12.025

[18] Iñiguez-Franco F., Auras R., Rubino M., Dolan K., Soto-Valdez H., Selke S.: Effect of nanoparticles on the hydrolytic degradation of PLA-nanocomposites by water-ethanol solutions. Polymer Degradation and Stability, 146, 287-297 (2017).

https://doi.org/10.1016/j.polymdegradstab.2017.11.004

[19] Rydz J., Wolna-Stypka K., Musioł M., Szeluga U., Janeczek H., Kowalczuk M.: Further evidence of polylactide degradation in paraffin and in selected protic media. A thermal analysis of eroded polylactide films. Polymer Degradation and Stability, 98, 1450-1457 (2013).

https://doi.org/10.1016/j.polymdegradstab.2013.05.005

[20] Tsuji H., Ikarashi K., Fukuda N.: Poly(L-lactide): XII. Formation, growth, and morphology of crystalline residues as extended-chain crystallites through hydrolysis of poly(L-lactide) films in phosphate-buffered solution. Polymer Degradation and Stability, 84, 515-523 (2004).

https://doi.org/10.1016/j.polymdegradstab.2004.01.010

[21] Antunes A., Popelka A., Aljarod O., Hassan M. K., Luyt A. S.: Effects of rutile- $\mathrm{TiO}_{2}$ nanoparticles on accelerated weathering degradation of poly(lactic acid). Polymers, 12, 1096/1-1096/25 (2020).

https://doi.org/10.3390/polym12051096

[22] Morent R., De Geyter N., Desmet T., Dubruel P., Leys C.: Plasma surface modification of biodegradable polymers: A review. Plasma Processes and Polymers, 8, 171-190 (2011). https://doi.org/10.1002/ppap.201000153 
[23] Chang S-H., Chian C-H.: Plasma surface modification effects on biodegradability and protein adsorption properties of chitosan films. Applied Surface Science, 282, 735-740 (2013).

https://doi.org/10.1016/j.apsusc.2013.06.044

[24] Fabbri M., Gigli M., Costa M., Govoni M., Seri P., Lotti N., Giordano E., Munari A., Gamberini R., Rimini B., Neretti G., Cristofolini A., Borghi C. A.: The effect of plasma surface modification on the biodegradation rate and biocompatibility of a poly(butylene succinate)based copolymer. Polymer Degradation and Stability, 121, 271-279 (2015).

https://doi.org/10.1016/j.polymdegradstab.2015.09.015

[25] Song A. Y., Oh Y. A., Roh S. H., Kim J. H., Min S. C.: Cold oxygen plasma treatments for the improvement of the physicochemical and biodegradable properties of polylactic acid films for food packaging. Journal of Food Science, 81, E86-E96 (2016).

https://doi.org/10.1111/1750-3841.13172

[26] Owens D. K., Wendt R. C.: Estimation of the surface free energy of polymers. Journal of Applied Polymer Science, 13, 1741-1747 (1969). https://doi.org/10.1002/app.1969.070130815

[27] Ostafinska A., Fortelny I., Nevoralova M., Hodan J., Kredatusova J., Slouf M.: Synergistic effects in mechanical properties of PLA/PCL blends with optimized composition, processing, and morphology. RSC Advances, 5, 98971-98982 (2015).

https://doi.org/10.1039/c5ra21178f

[28] Jordá-Vilaplana A., Fombuena V., García-García D., Samper M. D., Sánchez-Nácher L.: Surface modification of polylactic acid (PLA) by air atmospheric plasma treatment. European Polymer Journal, 58, 23-33 (2014).

https://doi.org/10.1016/j.eurpolymj.2014.06.002

[29] Vergne C., Buchheit O., Eddoumy F., Sorrenti E., Di Martino J., Ruch D.: Modifications of the polylactic acid surface properties by DBD plasma treatment at atmospheric pressure. Journal of Engineering Materials and Technology, 133, 30903/1-30903/7 (2011).

https://doi.org/10.1115/1.4004156

[30] Janorkar A. V., Metters A. T., Hirt D. E.: Modification of poly(lactic acid) films: Enhanced wettability from surface-confined photografting and increased degradation rate due to an artifact of the photografting process. Macromolecules, 37, 9151-9159 (2004).

https://doi.org/10.1021/ma049056u

[31] Hakkarainen M.: Aliphatic polyesters: Abiotic and biotic degradation and degradation products. in 'Degradable aliphatic polyesters' (ed.: Albertsson A-C.) Springer, Berlin, Vol 157, 113-138 (2002). https://doi.org/10.1007/3-540-45734-8_ 4

[32] Zhou Q., Xanthos M.: Nanoclay and crystallinity effects on the hydrolytic degradation of polylactides. Polymer Degradation and Stability, 93, 1450-1459 (2008).

https://doi.org/10.1016/j.polymdegradstab.2008.05.014
[33] Wiggins J. S., Hassan M. K., Mauritz K. A., Storey R. F.: Hydrolytic degradation of poly(D,L-lactide) as a function of end group: Carboxylic acid vs. hydroxyl. Polymer, 47, 1960-1969 (2006).

https://doi.org/10.1016/j.polymer.2006.01.021

[34] Junkar I.: Plasma treatment of amorphous and semicrystalline polymers for improved biocompatibility. Vacuum, 98, 111-115 (2013). https://doi.org/10.1016/j.vacuum.2012.11.006

[35] Shao J., Xu L., Pu S., Hou H.: The crystallization behavior of poly(L-lactide)/poly(D-lactide) blends: Effect of stirring time during solution mixing. Polymer Bulletin, 78, 147-163 (2020).

https://doi.org/10.1007/s00289-020-03103-9

[36] Jacobs T., Declercq H., de Geyter N., Cornelissen R., Dubruel P., Leys C., Beaurain A., Payen E., Morent R.: Plasma surface modification of polylactic acid to promote interaction with fibroblasts. Journal of Materials Science: Materials in Medicine, 24, 469-478 (2013). https://doi.org/10.1007/s10856-012-4807-z

[37] Siparsky G. L., Voorhees K. J., Dorgan J. R., Schilling K.: Water transport in polylactic acid (PLA), PLA/polycaprolactone copolymers, and PLA/polyethylene glycol blends. Journal of Environmental Polymer Degradation, 5, 125-136 (1997). https://doi.org/10.1007/BF02763656

[38] Móczó J., Kun D., Fekete E.: Desiccant effect of starch in polylactic acid composites. Express Polymer Letters, 12, 1014-1024 (2018). https://doi.org/10.3144/expresspolymlett.2018.88

[39] Araújo A., Botelho G. L., Silva M., Machado A. V.: UV stability of poly(lactic acid) nanocomposites. Journal of Materials Science and Engineering B, 3, 75-83 (2013). https://doi.org/10.17265/2161-6221/2013.02.001

[40] Varsavas S. D., Kaynak C.: Weathering degradation performance of PLA and its glass fiber reinforced composite. Materials Today Communications, 15, 344-353 (2018). https://doi.org/10.1016/j.mtcomm.2017.11.008

[41] Luo Y., Cao Y., Guo G.: Effects of $\mathrm{TiO}_{2}$ nanoparticles on the photodegradation of poly(lactic acid). Journal of Applied Polymer Science, 135, 46509/1-46509/8 (2018). https://doi.org/10.1002/app.46509

[42] Du W., Shao H., He Z., Tang C., Liu Y., Shen T., Zhu Y., Lau W-M., Hui D.: Cross-linking poly(lactic acid) film surface by neutral hyperthermal hydrogen molecule bombardment. Journal of Agricultural and Food Chemistry, 63, 10604-10610 (2015).

https://doi.org/10.1021/acs.jafc.5b04249

[43] Tverdokhlebov S. I., Bolbasov E. N., Shesterikov E. V., Antonova L. V., Golovkin A. S., Matveeva V. G., Petlin D. G., Anissimov Y. G.: Modification of polylactic acid surface using RF plasma discharge with sputter deposition of a hydroxyapatite target for increased biocompatibility. Applied Surface Science, 329, 32-39 (2015). https://doi.org/10.1016/j.apsusc.2014.12.127 
[44] Popelka A., Abdulkareem A., Mahmoud A. A., Nassr M. G., Al-Ruweidi M. K. A. A., Mohamoud K. J., Hussein M. K., Lehocky M., Vesela D., Humpolíček P., Kasak P.: Antimicrobial modification of PLA scaffolds with ascorbic and fumaric acids via plasma treatment. Surface and Coatings Technology, 400, 126216/1126216/12 (2020).

https://doi.org/10.1016/j.surfcoat.2020.126216

[45] Hergelová B., Zahoranová A., Kováčik D., Stupavská M., Černák M.: Polylactic acid surface activation by atmospheric pressure dielectric barrier discharge plasma. Open Chemistry, 13, 564-569 (2015).

https://doi.org/10.1515/chem-2015-0067

[46] Abusrafa A. E., Habib S., Krupa I., Ouederni M., Popelka A.: Modification of polyethylene by RF plasma in different/mixture gases. Coatings, 9, 145/1-145/24 (2019). https://doi.org/10.3390/coatings9020145

[47] Xu R., Xie J., Lei C.: Influence of melt-draw ratio on the crystalline behaviour of a polylactic acid cast film with a chi structure. RSC Advances, 7, 39914-39921 (2017). https://doi.org/10.1039/c7ra05422j

[48] Meaurio E., López-Rodríguez N., Sarasua J. R.: Infrared spectrum of poly(L-lactide): Application to crystallinity studies. Macromolecules, 39, 9291-9301 (2006). https://doi.org/10.1021/ma061890r

[49] Lv S., Liu X., Gu J., Jiang Y., Tan H., Zhang Y.: Effect of glycerol introduced into PLA based composites on the UV weathering behavior. Construction and Building Materials, 144, 525-531 (2017).

https://doi.org/10.1016/j.conbuildmat.2017.03.209

[50] De Geyter N., Morent R., Leys C.: Surface characterization of plasma-modified polyethylene by contact angle experiments and ATR-FTIR spectroscopy. Surface and Interface Analysis, 40, 608-611 (2008). https://doi.org/10.1002/sia.2611

[51] Cintrón M. S., Hinchliffe D. J.: FT-IR examination of the development of secondary cell wall in cotton fibers. Fibers, 3, 30-40 (2015). https://doi.org/10.3390/fib3010030

[52] Santonja-Blasco L., Ribes-Greus A., Alamo R. G.: Comparative thermal, biological and photodegradation kinetics of polylactide and effect on crystallization rates. Polymer Degradation and Stability, 98, 771-784 (2013). https://doi.org/10.1016/j.polymdegradstab.2012.12.012

[53] Chávez-Montes W. M., González-Sánchez G., LópezMartínez E. I., De Lira-Gómez P., Ballinas-Casarrubias L., Flores-Gallardo S.: Effect of artificial weathering on PLA/nanocomposite molecular weight distribution. Polymers, 7, 760-776 (2015). https://doi.org/10.3390/polym7040760

[54] Kmetty Á., Litauszki K.: Development of poly (lactide acid) foams with thermally expandable microspheres. Polymers, 12, 463/1-463/16 (2020). https://doi.org/10.3390/polym12020463
[55] Yoshida S., Hagiwara K., Hasebe T., Hotta A.: Surface modification of polymers by plasma treatments for the enhancement of biocompatibility and controlled drug release. Surface and Coatings Technology, 233, 99-107 (2013).

https://doi.org/10.1016/j.surfcoat.2013.02.042

[56] Ragoubi M., George B., Molina S., Bienaimé D., Merlin A., Hiver J-M., Dahoun A.: Effect of corona discharge treatment on mechanical and thermal properties of composites based on miscanthus fibres and polylactic acid or polypropylene matrix. Composites Part A: Applied Science and Manufacturing, 43, 675-685 (2012). https://doi.org/10.1016/j.compositesa.2011.12.025

[57] Díez-Pascual A. M., Díez-Vicente A. L.: ZnO-reinforced poly(3-hydroxybutyrate-co-3-hydroxyvalerate) bionanocomposites with antimicrobial function for food packaging. ACS Applied Materials and Interfaces, 6, 9822-9834 (2014).

https://doi.org/10.1021/am502261e

[58] Gorrasi G., Milone C., Piperopoulos E., Lanza M., Sorrentino A.: Hybrid clay mineral-carbon nanotube-PLA nanocomposite films. Preparation and photodegradation effect on their mechanical, thermal and electrical properties. Applied Clay Science, 71, 49-54 (2013). https://doi.org/10.1016/j.clay.2012.11.004

[59] Zhang H., Huang J., Yang L., Chen R., Zou W., Lin X., $\mathrm{Qu}$ J.: Preparation, characterization and properties of $\mathrm{PLA} / \mathrm{TiO}_{2}$ nanocomposites based on a novel vane extruder. RSC Advances, 5, 4639-4647 (2015). https://doi.org/10.1039/c4ra14538k

[60] Luo Y., Lin Z., Guo G.: Biodegradation assessment of poly (lactic acid) filled with functionalized titania nanoparticles $\left(\mathrm{PLA} / \mathrm{TiO}_{2}\right)$ under compost conditions. Nanoscale Research Letters, 14, 56/1-56/10 (2019). https://doi.org/10.1186/s11671-019-2891-4

[61] Luo Y-B., Wang X-L., Wang Y-Z.: Effect of $\mathrm{TiO}_{2}$ nanoparticles on the long-term hydrolytic degradation behavior of PLA. Polymer Degradation and Stability, 97, 721-728 (2012). https://doi.org/10.1016/j.polymdegradstab.2012.02.011

[62] Litauszki K., Kovács Z., Mészáros L., Kmetty Á.: Accelerated photodegradation of poly(lactic acid) with weathering test chamber and laser exposure - A comparative study. Polymer Testing, 76, 411-419 (2019). https://doi.org/10.1016/j.polymertesting.2019.03.038

[63] Deroiné M., Le Duigou A., Corre Y-M., Le Gac P-Y., Davies P., César G., Bruzaud S.: Accelerated ageing of polylactide in aqueous environments: Comparative study between distilled water and seawater. Polymer Degradation and Stability, 108, 319-329 (2014). https://doi.org/10.1016/j.polymdegradstab.2014.01.020

[64] Iñiguez-franco F., Auras R., Rubino M., Dolan K., Soto-Valdez H., Selke S.: Effect of nanoparticles on the hydrolytic degradation of PLA-nanocomposites by water-ethanol solutions. Polymer Degradation and Stability, 146, 287-297 (2017).

https://doi.org/10.1016/j.polymdegradstab.2017.11.004 
[65] Battegazzore D., Bocchini S., Frache A.: Crystallization kinetics of poly(lactic acid)-talc composites. Express Polymer Letters, 5, 849-858 (2011).

https://doi.org/10.3144/expresspolymlett.2011.84

[66] Pluta M.: Melt compounding of polylactide/organoclay: Structure and properties of nanocomposites. Journal of Polymer Science Part B: Polymer Physics, 44, 33923405 (2006).

https://doi.org/10.1002/polb.20957

[67] Rocca-Smith J. R., Karbowiak T., Marcuzzo E., Sensidoni A., Piasente F., Champion D., Heinz O., Vitry P., Bourillot E., Lesniewska E., Debeaufort F.: Impact of corona treatment on PLA film properties. Polymer Degradation and Stability, 132, 109-116 (2016). https://doi.org/10.1016/j.polymdegradstab.2016.03.020
[68] Slepička P., Slepičková Kasálková N. S., Stránská E., Bačáková L., Švorčík V.: Surface characterization of plasma treated polymers for applications as biocompatible carriers. Express Polymer Letters, 7, 535-545 (2013).

https://doi.org/10.3144/expresspolymlett.2013.50

[69] Vesel A., Primc G., Zaplotnik R., Mozetič M.: Applications of highly non-equilibrium low-pressure oxygen plasma for treatment of polymers and polymer composites on an industrial scale. Plasma Physics and Controlled Fusion, 62, 024008/1-024008/9 (2020). https://doi.org/10.1088/1361-6587/ab5b50

[70] Gleadall A.: Mechanical properties of biodegradable polymers for medical applications. in 'Modelling degradation of bioresorbable polymeric medical devices' (ed.: Pan J.) Woodhead Publishing, Cambridge, 163199 (2015). 